Article

\title{
Design, Synthesis, and In Vitro Evaluation of Benzofuro[3,2-c]Quinoline Derivatives as Potential Antileukemia Agents
}

\author{
Ying Lin ${ }^{1}$, Dong Xing ${ }^{1}$, Wen-Biao $\mathrm{Wu}^{2,3}$, Gao-Ya Xu ${ }^{2,3}$, Li-Fang Yu ${ }^{1}{ }^{\circledR}$, Jie Tang ${ }^{1,4}$, \\ Yu-Bo Zhou ${ }^{2,3}$, Jia Li ${ }^{2,3,5, *}$ and Fan Yang ${ }^{1, *(D)}$ \\ 1 Shanghai Engineering Research Center of Molecular Therapeutics and New Drug Development, \\ School of Chemistry and Molecular Engineering, East China Normal University, Shanghai 200062, China; \\ shanghailinying902@163.com (Y.L.); dxing@sat.ecnu.edu.cn (D.X.); lfyu@sat.ecnu.edu.cn (L.-F.Y.); \\ jtang@chem.ecnu.edu.cn (J.T.) \\ 2 National Center for Drug Screening, Shanghai Institute of Material Medica, Chinese Academy of Science, \\ Shanghai 201203, China; s18-wuwenbiao@simm.ac.cn (W.-B.W.); gyxu@simm.ac.cn (G.-Y.X.); \\ ybzhou@simm.ac.cn (Y.-B.Z.) \\ 3 University of Chinese Academy of Sciences, No. 19A Yuquan Road, Beijing 100049, China \\ 4 Shanghai Greenchem \& Biotech Co. Ltd., Shanghai 200062, China \\ 5 Open Studio for Druggability Research of Marine Natural Products, Pilot National Laboratory for Marine \\ Science and Technology (Qingdao), 1 Wenhai Road, Aoshanwei, Jimo, Qingdao 266237, China \\ * Correspondence: jli@simm.ac.cn (J.L.); fyang@chem.ecnu.edu.cn (F.Y.); \\ Tel.: +86-21-5080-6600 (J.L.); +86-21-6223-2764 (F.Y.)
}

Received: 14 December 2019; Accepted: 1 January 2020; Published: 3 January 2020

check for updates

\begin{abstract}
Herein, we design and synthesize an array of benzofuro[3,2-c]quinolines starting from 3-(2-methoxyphenyl)quinolin-4(1H)ones via a sequential chlorination/demethylation, intramolecular cyclization pathway. This sequential transformation was efficient, conducted under metal-free and mild reaction conditions, and yielded corresponding benzofuro[3,2-c]quinolines in high yields. In vitro biological evaluation indicated that such type of compounds showed excellent antileukemia activity and selectivity, and therefore may offer a promising hit compound for developing antileukemia compounds.
\end{abstract}

Keywords: benzofuro[3,2-c]quinolines; 3-(2-methoxyphenyl)quinolin-4(1H)one; MV-4-11 cell line; antileukemia activity

\section{Introduction}

Furo[3,2-c]pyridines belong to a novel class of heterocycles that exhibit a wide range of biological activities [1-3]. A large number of heterocyclic compounds bearing a furo[3,2-c]pyridine core have been reported as anticancer (Figure 1A, compounds $\mathbf{A}$ and $\mathbf{B}$ ) $[4,5]$ or antibacterial agents (Figure 1A, compound C) [6]. Among them, the tricyclic furo[3,2-c]quinoline skeleton possessing a fused aryl ring on the pyridine part has also shown unique pharmaceutical and biological activities. For example, compound $\mathbf{D}$ has been found to be a neuroprotective agent [7]. Compound $\mathbf{E}$ was reported to be a potent antiproliferative molecule against renal UO-31, melanoma UACC-257, and UACC-62 cell lines [8]. Agrawal et al. reported that compound $\mathbf{F}$ may be a potential topoisomerase-II inhibitor based on related computational studies [9]. In view of the diverse biological activities of such molecules, the design and synthesis of novel heterocyclic structures possessing the furo[3,2-c]pyridine skeleton would be highly valuable for biological studies. As our continuous research interest, herein we design and synthesize a new type of tetracyclic benzofuro[3,2-c]quinoline (Figure 1B, compound G) that contains 
the key furo[3,2-c]pyridine skeleton by introducing a fused aryl ring on the furan side. Although such types of tetracyclic heterocycles have been reported by several research groups, related biological studies are still very limited [10]. Based on our newly synthesized compounds, an in vitro biological evaluation was then conducted.

Recently, our group has developed an efficient route for the synthesis of 3-(2-methoxyphenyl)quinolin-4(1H)-ones 1 via an in situ Meinwald rearrangement/intramolecular reductive cyclization of chalcone epoxides (Figure 1B) [11,12]. This transformation was easily scaled up, showed a broad substrate scope, and tolerated a variety of functional groups. With this method developed, we envisioned that an efficient synthesis of benzofuro[3,2-c]quinoline $\mathrm{G}$ could be designed via demethylation followed by either one-pot or stepwise cyclization starting from 3-(2-methoxyphenyl)quinolin-4(1H)-ones 1 (Figure 1B). A batch of methods for the synthesis of such compounds have been reported, such as the palladium-catalyzed aromatization reaction [10], O-arylation/dehydrogenative cross-coupling reaction [13], C-O coupling reaction [14], demethyl-cyclization reaction [15], and many others [16-18]. The current method is featured due to it using a readily accessible starting material and involving the easy installation of different functional groups and the mild and metal-free reaction conditions to access a number of substituted benzofuro[3,2-c] quinoline derivatives for in vitro biological evaluations. Furthermore, it was found that this type of compound showed promising antileukemia activities.

A) Representative examples of biologically active furo[3,2-c]pyridines

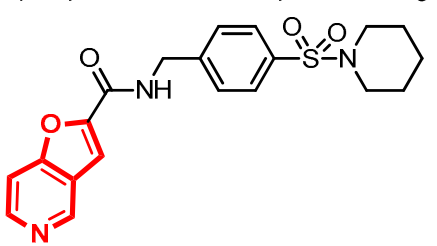

A

ovarian cancer

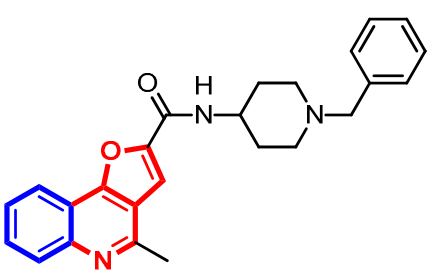

D

Alzheimer's disease

B) designed synthesis of benzof

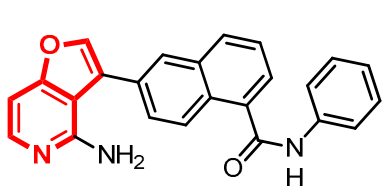

B

VEGFR-2 inhibitor

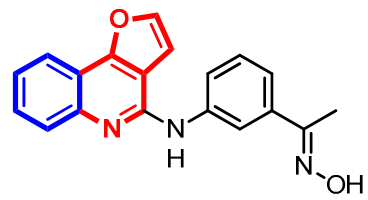

E

renal cancer and melanoma

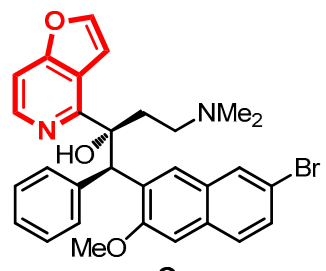

C

anti-tuberculosis<smiles>CC(=O)c1ccc(Nc2nc3ccccc3c3occc23)cc1</smiles>

topoisomerase-II inhibitor

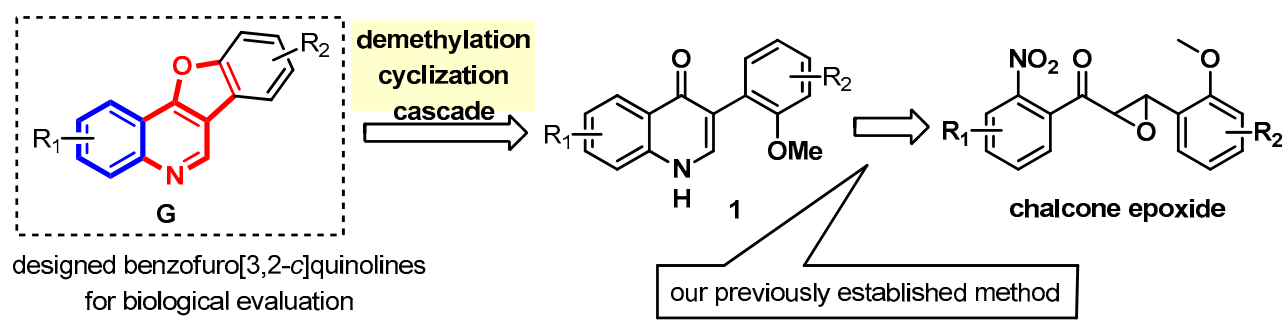

Figure 1. (a) Representative biologically active heterocycles bearing a furo[3,2-c]pyridine skeleton and (b) the proposed synthesis method for tetracyclic benzofuro[3,2-c]quinolines.

\section{Results and Discussion}

\subsection{Chemistry}

Initially, 3-(2-methoxyphenyl)quinolin-4(1H)-one 1a, which was conveniently obtained from the corresponding chalcone epoxide, was chosen as the model substrate for the synthesis of 
benzofuro[3,2-c]quinoline 2a via a demethylation/cyclization cascade. However, upon a thorough condition screening, the formation of $2 \mathbf{a}$ could not be observed at all [Supplementary materials]. In order to access the desired product $\mathbf{2} \mathbf{a}$ from the readily available starting substrate $\mathbf{1} \mathbf{a}$, a stepwise reaction was then developed (Scheme 1). First, by treating with suitable chlorination reagents, 1a was converted into the corresponding 4-chloroquinine 3a. Upon carefully investigating condition optimizations, $\mathrm{SOCl}_{2}$ was found to be the most effective, yielding 3 a with a $93 \%$ yield using $\mathrm{CH}_{2} \mathrm{Cl}_{2}$ as the solvent. Treating 3a with $48 \% \mathrm{HBr}$ under reflux gave the demethylation product 4 a with a $98 \%$ yield. The chlorination and demethylation steps were conducted in a one-pot manner without the isolation of $\mathbf{3 a}$, and the overall yield of $\mathbf{4 a}$ was maintained at a high level (96\%). Finally, a simple intramolecular annulation of $\mathbf{4 a}$ with $\mathrm{KO} t$-Bu led to the formation of the expected benzofuro[3,2-c]quinoline $2 \mathbf{a}$ with a high yield [Supplementary materials].

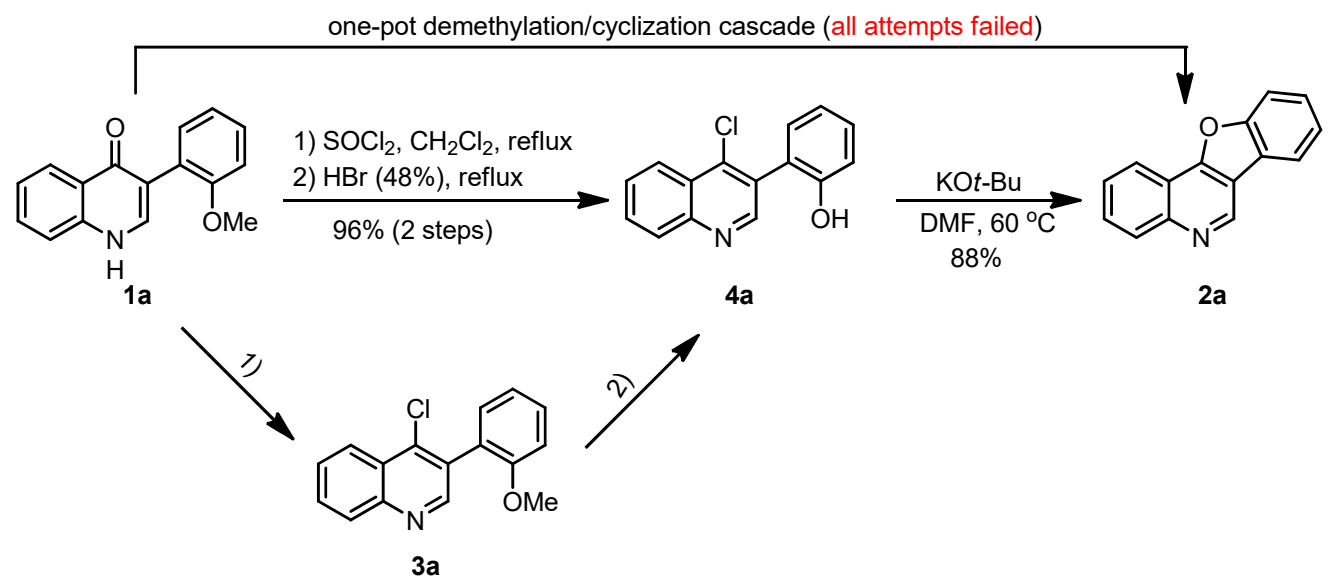

Scheme 1. Successful synthesis of benzofuro[3,2-c]quinoline 2a from 1a via a stepwise chlorination/demethylation/cyclization.

With the optimized reaction conditions identified, the scope of this stepwise chlorination/demethylation/cyclization transformation was investigated by preparing different substituted benzofuro[3,2-c]quinolines (Table 1). Several substrates bearing different functional groups on both the benzofuran and the quinoline were prepared and subjected to the standard reaction conditions. Halogen substituents at different positions on the benzofuran ring were all well tolerated, giving the corresponding tetracyclic products in high overall yields $(\mathbf{2} \mathbf{c}, \mathbf{2} \mathbf{f}-\mathbf{2 i})$. A substrate bearing a trifluoromethoxyl substituent on the benzofuran ring also worked well (2k). With the methyl substituent at different positions on the benzofuran ring, this two-step transformation ran

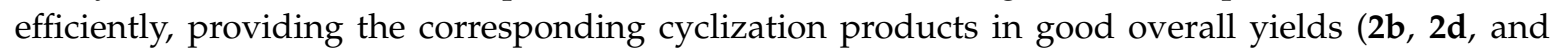
$2 j$ ). The substrate scope with different substituents on the quinoline moiety was then investigated. Both the electron-donating methyl substituent (2n, 2p, 2t, and 2v) and electron-withdrawing halogen substituents (2o and $\mathbf{2 r}-\mathbf{2 s}$ ) at different positions all gave the corresponding cyclization products in good overall yields. A free hydroxyl substituent was introduced to different positions on both the benzofuran and quinoline rings, with the aim of increasing the potential biological activities of these molecules [19-21]. While the one-pot chlorination/demethylation step was still very efficient, the subsequent base-promoted cyclization for these hydroxyl-substituted substrates generally gave low yields of the corresponding cyclization products. The low yield of the second step may have come from the competitive reactions between the free hydroxyl groups with the base $(\mathbf{2} \mathbf{e}, \mathbf{2} \mathbf{1}, \mathbf{2} \mathbf{q}, \mathbf{2} \mathbf{u}$, and $\mathbf{2} \mathbf{w}-\mathbf{2} \mathbf{x})$, and we speculate that the low yields of the second steps may be improved via selective protection of the hydroxyl group, which is not involved in the cyclization reaction. 
Table 1. Substrate scope ${ }^{1}$.

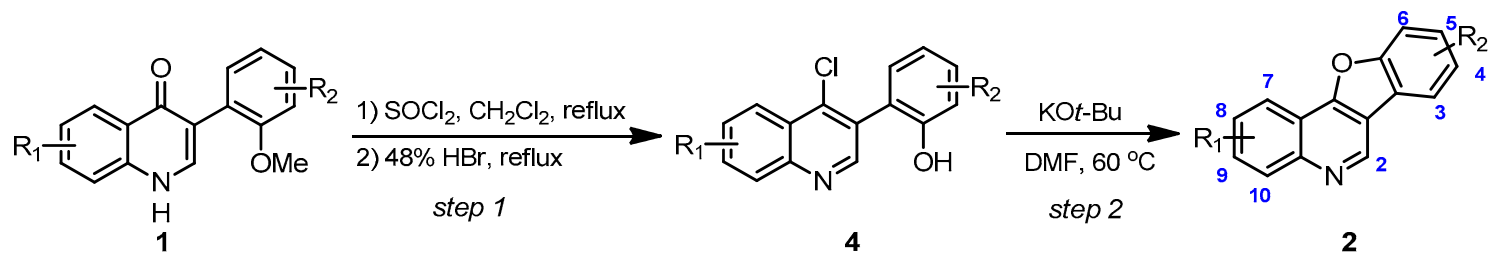

\begin{tabular}{|c|c|c|c|c|c|}
\hline Entry & 2 & $\mathbf{R}_{\mathbf{1}}$ & $\mathbf{R}_{2}$ & Yield of Step $1(\%)$ & Yield of Step $2(\%)$ \\
\hline 1 & $2 a$ & $\mathrm{H}$ & $\mathrm{H}$ & 98 & 88 \\
\hline 2 & $2 b$ & $\mathrm{H}$ & 6-Me & 90 & 72 \\
\hline 3 & $2 c$ & $\mathrm{H}$ & $6-\mathrm{F}$ & 87 & 82 \\
\hline 4 & $2 d$ & $\mathrm{H}$ & 5-Me & 81 & 92 \\
\hline 5 & $2 e$ & $\mathrm{H}$ & $5-\mathrm{OH}$ & 90 & 12 \\
\hline 6 & $2 f$ & $\mathrm{H}$ & $5-\mathrm{Br}$ & 94 & 85 \\
\hline 7 & $2 \mathrm{~g}$ & $\mathrm{H}$ & $5-\mathrm{Cl}$ & 88 & 75 \\
\hline 8 & $2 \mathrm{~h}$ & $\mathrm{H}$ & $4-\mathrm{F}$ & 80 & 89 \\
\hline 9 & $2 \mathbf{i}$ & $\mathrm{H}$ & $4-\mathrm{Cl}$ & 95 & 86 \\
\hline 10 & $2 j$ & $\mathrm{H}$ & 4-Me & 92 & 94 \\
\hline 11 & $2 k$ & $\mathrm{H}$ & $4-\mathrm{OCF}_{3}$ & 85 & 62 \\
\hline 12 & 21 & $\mathrm{H}$ & $4-\mathrm{OH}$ & 68 & 23 \\
\hline 13 & $2 m$ & $\mathrm{H}$ & $3-\mathrm{Cl}$ & 94 & 42 \\
\hline 14 & $2 n$ & 7-Me & $\mathrm{H}$ & 95 & 85 \\
\hline 15 & 20 & $8-\mathrm{Cl}$ & $\mathrm{H}$ & 94 & 91 \\
\hline 16 & $2 p$ & 8-Me & $\mathrm{H}$ & 86 & 83 \\
\hline 17 & $2 q$ & $8-\mathrm{OH}$ & $\mathrm{H}$ & 90 & 10 \\
\hline 18 & $2 r$ & 9-F & $\mathrm{H}$ & 92 & 77 \\
\hline 19 & $2 s$ & 9-Cl & $\mathrm{H}$ & 90 & 69 \\
\hline 20 & $2 t$ & 9-Me & $\mathrm{H}$ & 86 & 92 \\
\hline 21 & $2 u$ & 9-OH & $\mathrm{H}$ & 87 & 14 \\
\hline 22 & $2 v$ & 10-Me & $\mathrm{H}$ & 91 & 79 \\
\hline 23 & $2 w$ & $9-\mathrm{Br}$ & $4-\mathrm{OH}$ & 97 & 17 \\
\hline 24 & $2 x$ & 9-Cl & $4-\mathrm{OH}$ & 91 & 12 \\
\hline
\end{tabular}

${ }^{1}$ Reaction conditions: 1 (1 mmol), $\mathrm{SOCl}_{2}$ (4 equiv.), $\mathrm{CH}_{2} \mathrm{Cl}_{2}(5 \mathrm{~mL}), 48 \% \mathrm{HBr}(5 \mathrm{~mL}), 4$ (1 equiv.), $\mathrm{KO} t$ - $\mathrm{Bu}$ (2 equiv.), $\mathrm{N}, \mathrm{N}$-dimethylformamide (DMF) $(5 \mathrm{~mL})$.

\subsection{Benzofuro[3,2-c]Quinoline Inhibition Studies}

With these newly synthesized benzofuro[3,2-c]quinoline derivatives available, their in vitro antileukemia activities were evaluated against the MV-4-11 cell line, which is one of the acute myelocytic leukemia (AML) cell lines (Table 2) [22,23]. As shown in Table 2, most of these compounds, except for $\mathbf{2 h}, \mathbf{2 k}-\mathbf{2} \mathbf{m}$, and $\mathbf{2 v}$, exhibited good antileukemia activity against MV-4-11 cells. Among them, compound 2e, possessing a free hydroxyl group at the $\mathrm{C} 5$ position on the benzofuran ring, showed the highest antileukemia activity $\left(\mathrm{IC}_{50}=0.12 \mu \mathrm{M}\right)$. When the free hydroxyl group was replaced with $\mathrm{Cl}$ or $\mathrm{CH}_{3}$, the activities decreased 10 -fold $(2 \mathbf{d}$ and $\mathbf{2 g}$ ). Compound $\mathbf{2 q}$, bearing a free hydroxyl group at $\mathrm{C} 8$ on the quinoline ring, also showed promising antileukemia activity $\left(\mathrm{IC}_{50}=0.24 \mu \mathrm{M}\right)$. Similarly, when this hydroxyl substituent was replaced with $\mathrm{Cl}$, the activity was reduce 10-fold (2o). On the other hand, replacing this hydroxyl group with methyl resulted in a slightly decreased activity (2p). Methyl, halogen, or hydroxyl substitutions at C3 showed only a slight difference on antileukemia activity $(\mathbf{2} \mathbf{r}-\mathbf{2} \mathbf{u})$. As concluded from these results, compounds with hydroxyl substitution $(\mathbf{2 e}, \mathbf{2 q}$, and 2u) generally exhibited good activities; however, compounds bearing a free hydroxyl group at $\mathrm{C} 4$ of the benzofuran ring ( 21 and $\mathbf{2 x}$ ) did not lead to increased activities. 
Table 2. In vitro antileukemia activity of benzofuro[3,2-c]quinoline derivatives against the growth of the MV-4-11 cell line.

\begin{tabular}{cccc}
\hline Compound & $\mathbf{M V}-\mathbf{- 4}-\mathbf{1 1}{ }^{\mathbf{1}} \mathbf{I C}_{\mathbf{5 0}}(\boldsymbol{\mu M})$ & Compound & MV-4-11 ${ }^{\mathbf{1}} \mathbf{I C}_{\mathbf{5 0}}(\boldsymbol{\mu M})$ \\
\hline $\mathbf{2 a}$ & $2.40 \pm 0.30$ & $\mathbf{2 p}$ & $0.40 \pm 0.068$ \\
$\mathbf{2 c}$ & $2.27 \pm 0.33$ & $\mathbf{2 q}$ & $0.24 \pm 0.10$ \\
$\mathbf{2 d}$ & $4.34 \pm 3.40$ & $\mathbf{2 r}$ & $1.15 \pm 0.35$ \\
$\mathbf{2 e}$ & $0.12 \pm 0.044$ & $\mathbf{2 s}$ & $1.91 \pm 0.16$ \\
$\mathbf{2 g}$ & $3.60 \pm 1.30$ & $\mathbf{2 t}$ & $1.22 \pm 0.26$ \\
$\mathbf{2 h}$ & $>20^{2}$ & $\mathbf{2 u}$ & $0.80 \pm 0.29$ \\
$\mathbf{2 k}$ & $>20$ & $\mathbf{2 v}$ & $>20$ \\
$\mathbf{2}$ & $>20$ & $\mathbf{2 x}$ & $16.39 \pm 10.94$ \\
$\mathbf{2}$ & $>20$ & Cisplatin & $>20$ \\
$\mathbf{2 n}$ & $9.21 \pm 3.20$ & Sunitinib & $<0.01^{3}$ \\
$\mathbf{2 0}$ & $2.84 \pm 0.33$ & & \\
\hline
\end{tabular}

From the MTS assay after $72 \mathrm{~h}$ of treatment. ${ }^{1} \mathrm{IC}_{50}$ data is an average of at least three independent experiments. ${ }^{2}$ $>\mathrm{IC}_{50}$ value was above the highest concentration used in the assay. ${ }^{3}$ From Nemes et al. [24].

It is vital to examine the cytotoxicity on normal cells during the development of an anticancer drug. Accordingly, four compounds that showed high antileukemia activities-2e, $\mathbf{2 p}, \mathbf{2 q}$, and $\mathbf{2} \mathbf{u}-$ were selected for the selectivity test on peripheral blood mononuclear cells (PBMCs) using an MTS assay (Table 3). The selectivity indexes (SIs) were counted by dividing the $\mathrm{IC}_{50}$ values in a PBMC by the $\mathrm{IC}_{50}$ values in MV-4-11 cell lines [25]. It was obvious that benzofuro[3,2-c]quinolines were less toxic on human peripheral blood mononuclear cell compared to human leukemia MV-4-11 cells. The most active compound, $2 \mathrm{e}(\mathrm{SI}=79.5)$, showed a 79.5 times higher selectivity toward cancer cells than toward normal cells.

Table 3. Cytotoxic activity of benzofuro[3,2-c] quinoline derivatives against the growth of peripheral blood mononuclear cells (PBMCs).

\begin{tabular}{cccc}
\hline Compound & PBMC $^{\mathbf{1}} \mathbf{I C}_{\mathbf{5 0}}(\boldsymbol{\mu M})$ & $\mathbf{M V}_{\mathbf{4}-\mathbf{1 1}}{ }^{\mathbf{1}} \mathbf{I C}_{\mathbf{5 0}}(\boldsymbol{\mu M})$ & SI $^{\mathbf{2}}$ \\
$\mathbf{2 e}$ & $9.54 \pm 0.063$ & $0.12 \pm 0.044$ & 79.5 \\
$\mathbf{2} \mathbf{p}$ & $>10^{3}$ & $0.40 \pm 0.068$ & $>25$ \\
$\mathbf{2 q}$ & $>10$ & $0.24 \pm 0.10$ & $>42$ \\
$\mathbf{2 u}$ & $>10$ & $0.80 \pm 0.29$ & $>12.5$ \\
\hline
\end{tabular}

From the MTS assay after $72 \mathrm{~h}$ of treatment ${ }^{1} \mathrm{IC}_{50}$ data is an average of at least three independent experiments. ${ }^{2} \mathrm{SI}$ : selectivity index. ${ }^{3}>\mathrm{IC}_{50}$ value was above the highest concentration used in the assay.

\section{Materials and Methods}

\subsection{Chemical Synthesis}

\subsubsection{General}

All reagents were commercially available and used without purification. The progress of the reactions was monitored using silica gel thin-layer chromatography (TLC). Flash column chromatography was conducted using silica gel (Yantai Kangbinuo, ShanDong, Yantai, China, 200-300). ${ }^{1} \mathrm{H}$ - and ${ }^{13} \mathrm{C}-\mathrm{NMR}$ spectra (Bruker Ascend, Bremen, Germany) were recorded at 400 and $100 \mathrm{MHz}$, respectively, using TMS (trimethyl chlorosilane) as the internal standard. Melting points were measured using a WRR-Y drug melting point measurement (Shanghai INESA Physico-Optical Instrument Co. Ltd, Shanghai, China). The high-resolution mass spectra were recorded on a Bruker micOTOF II spectrometer (Electrospray Ionization). 
3.1.2. General Procedures for the Synthesis of 2-(4-Chloroquinolin-3-Y1)Phenol Substrates $\mathbf{4 a - 4 x}$

A mixture of the substituted 3-phenylquinolin-4(1H)-one (1 equiv.), $\mathrm{SOCl}_{2}$ (4 equiv.), dichloromethane $(5 \mathrm{~mL})$ was refluxed until the reaction was completed $(1 \mathrm{~h})$, as evidenced using thin-layer chromatography (petroleum ether/ethyl acetate, 10:1). The cooled reaction mixture was concentrated in vacuo, diluted with water, then extracted with dichloromethane $(3 \times 20 \mathrm{~mL})$. The combined organic layer were washed with water and brine, dried with anhydrous $\mathrm{Na}_{2} \mathrm{SO}_{4}$, and concentrated in vacuo. Then, the crude mixture was refluxed under $48 \% \mathrm{HBr}$ without further purification until the reaction was completed. The mixture was poured into ice water and neutralized with saturated $\mathrm{NaHCO}_{3}$. The aqueous phase was extracted with ethyl acetate $(3 \times 20 \mathrm{~mL})$, dried with anhydrous $\mathrm{Na}_{2} \mathrm{SO}_{4}$, and concentrated in vacuo. The crude mixture was purified using column chromatography over a silica gel using dichloromethane/methanol (80:1) as an eluent.

2-(4-Chloroquinolin-3-yl)phenol (4a): White solid (0.25 g, 96\%), ${ }^{1} \mathrm{H}-\mathrm{NMR}\left(400 \mathrm{MHz}, \mathrm{DMSO}-d_{6}\right) \delta 9.76(\mathrm{~s}$, $1 \mathrm{H}), 8.78(\mathrm{~s}, 1 \mathrm{H}), 8.29(\mathrm{~d}, J=8.3 \mathrm{~Hz}, 1 \mathrm{H}), 8.13(\mathrm{~d}, J=8.3 \mathrm{~Hz}, 1 \mathrm{H}), 7.89(\mathrm{dd}, J=7.5,4.1 \mathrm{~Hz}, 1 \mathrm{H}), 7.80(\mathrm{dd}$, $J=7.8,7.5 \mathrm{~Hz}, 1 \mathrm{H}), 7.34-7.28(\mathrm{~m}, 2 \mathrm{H}), 7.02(\mathrm{~d}, J=8.1 \mathrm{~Hz}, 1 \mathrm{H}), 6.96(\mathrm{dd}, J=7.4,7.3 \mathrm{~Hz}, 1 \mathrm{H}) .{ }^{13} \mathrm{C}-\mathrm{NMR}$ $\left(100 \mathrm{MHz}, \mathrm{DMSO}-d_{6}\right) \delta 154.9,152.2,147.3,139.6,131.2,130.9,130.2,130.0,129.3,128.2,125.6,124.0$, $122.8,119.0,115.8$.

2-(4-Chloroquinolin-3-yl)-6-methylphenol (4b): Orange solid $(0.21 \mathrm{~g}, 78 \%),{ }^{1} \mathrm{H}-\mathrm{NMR}\left(400 \mathrm{MHz}, \mathrm{CDCl}_{3}\right) \delta$ $8.94(\mathrm{~s}, 1 \mathrm{H}), 8.47-8.44(\mathrm{~m}, 1 \mathrm{H}), 8.36(\mathrm{~d}, J=8.2 \mathrm{~Hz}, 1 \mathrm{H}), 8.04-8.01(\mathrm{~m}, 1 \mathrm{H}), 7.92-7.88(\mathrm{~m}, 1 \mathrm{H}), 7.15(\mathrm{~d}$, $J=4.6 \mathrm{~Hz}, 1 \mathrm{H}), 7.01(\mathrm{~d}, J=5.7 \mathrm{~Hz}, 1 \mathrm{H}), 6.84-6.81(\mathrm{~m}, 1 \mathrm{H}), 2.18(\mathrm{~s}, 3 \mathrm{H}) .{ }^{13} \mathrm{C}-\mathrm{NMR}\left(100 \mathrm{MHz}, \mathrm{CDCl}_{3}\right) \delta$ 156.5, 156.3, 149.8, 140.7, 139.2, 137.2, 137.0, 135.3, 132.4, 131.8, 130.2, 130.0, 125.1, 124.3, 124.0, 20.2.

2-(4-Chloroquinolin-3-yl)-6-fluorophenol (4c): Yellow solid (0.24 g, 87\%), ${ }^{1} \mathrm{H}-\mathrm{NMR}\left(400 \mathrm{MHz}, \mathrm{DMSO}-d_{6}\right) \delta$ 9.94 (br s, 1H), $8.91(\mathrm{~s}, 1 \mathrm{H}), 8.34(\mathrm{~d}, J=8.1 \mathrm{~Hz}, 1 \mathrm{H}), 8.18(\mathrm{~d}, J=8.3 \mathrm{~Hz}, 1 \mathrm{H}), 7.97(\mathrm{dd}, J=7.6,7.1 \mathrm{~Hz}, 1 \mathrm{H})$, $7.86(\mathrm{dd}, J=7.5,7.4 \mathrm{~Hz}, 1 \mathrm{H}), 7.35-7.30(\mathrm{~m}, 1 \mathrm{H}), 7.14(\mathrm{~d}, J=7.6 \mathrm{~Hz}, 1 \mathrm{H}), 6.97(\mathrm{ddd}, J=8.0,7.9,5.0 \mathrm{~Hz}$, 1H). ${ }^{13} \mathrm{C}-\mathrm{NMR}\left(100 \mathrm{MHz}, \mathrm{DMSO}-\mathrm{d}_{6}\right) \delta 151.7\left(\mathrm{~d}, \mathrm{~J}_{\mathrm{C}-\mathrm{F}}=238.1 \mathrm{~Hz}\right), 150.9,145.7,142.7\left(\mathrm{~d}, \mathrm{~J}_{\mathrm{C}-\mathrm{F}}=14.6 \mathrm{~Hz}\right)$, $141.8,131.3,129.8\left(\mathrm{~d}, \mathrm{~J}_{\mathrm{C}-\mathrm{F}}=3.0 \mathrm{~Hz}\right), 128.9,128.0,126.6\left(\mathrm{~d}, \mathrm{~J}_{\mathrm{C}-\mathrm{F}}=2.8 \mathrm{~Hz}\right), 125.7,125.5\left(\mathrm{~d}, \mathrm{~J}_{\mathrm{C}-\mathrm{F}}=3.3 \mathrm{~Hz}\right)$, $124.3,119.3\left(\mathrm{~d}, \mathrm{~J}_{\mathrm{C}-\mathrm{F}}=7.4 \mathrm{~Hz}\right), 116.5\left(\mathrm{~d}, \mathrm{~J}_{\mathrm{C}-\mathrm{F}}=18.2 \mathrm{~Hz}\right)$.

2-(4-Chloroquinolin-3-yl)-5-methylphenol (4d): Yellow-green solid (0.22 g, 81\%), ${ }^{1} \mathrm{H}-\mathrm{NMR}(400 \mathrm{MHz}$, DMSO-d $) \delta 9.64($ br s, $1 \mathrm{H}), 8.76(\mathrm{~s}, 1 \mathrm{H}), 8.28(\mathrm{~d}, J=8.2 \mathrm{~Hz}, 1 \mathrm{H}), 8.12(\mathrm{~d}, J=7.9 \mathrm{~Hz}, 1 \mathrm{H}), 7.88(\mathrm{dd}, J=7.4$, $7.2 \mathrm{~Hz}, 1 \mathrm{H}), 7.79(\mathrm{dd} J=7.1,7.0 \mathrm{~Hz}, 1 \mathrm{H}), 7.16(\mathrm{~d}, J=7.6 \mathrm{~Hz}, 1 \mathrm{H}), 6.82(\mathrm{~s}, 1 \mathrm{H}), 6.77(\mathrm{~d}, J=7.5 \mathrm{~Hz}, 1 \mathrm{H})$, $2.31(\mathrm{~s}, 3 \mathrm{H}) .{ }^{13} \mathrm{C}-\mathrm{NMR}\left(100 \mathrm{MHz}, \mathrm{DMSO}-d_{6}\right) \delta 154.7,152.3,147.1,139.6(2 \mathrm{C}), 130.9,130.2,129.2,128.2$, $125.6,124.0(2 \mathrm{C}), 119.9,119.8,116.3,21.0$.

4-(4-Chloroquinolin-3-yl)benzene-1,3-diol (4e): Black oil (0.24 g, 90\%), ${ }^{1} \mathrm{H}-\mathrm{NMR}\left(400 \mathrm{MHz}, \mathrm{CD}_{3} \mathrm{OD} / \mathrm{CDCl}_{3}\right.$ $=2 / 3) \delta 8.89-8.88(\mathrm{~m}, 1 \mathrm{H}), 8.38-8.36(\mathrm{~m}, 2 \mathrm{H}), 7.96-7.92(\mathrm{~m}, 1 \mathrm{H}), 7.87-7.81(\mathrm{~m}, 1 \mathrm{H}), 7.02(\mathrm{dd}, \mathrm{J}=8.3$, $6.8 \mathrm{~Hz}, 1 \mathrm{H}), 6.47-6.46(\mathrm{~m}, 1 \mathrm{H}), 6.35(\mathrm{dd}, J=6.8,6.4 \mathrm{~Hz}, 1 \mathrm{H}) .{ }^{13} \mathrm{C}-\mathrm{NMR}\left(100 \mathrm{MHz}, \mathrm{CD}_{3} \mathrm{OD} / \mathrm{CDCl}_{3}=2 / 3\right)$ $\delta$ 157.4, 153.0, 148.7, 143.7, 134.1, 131.9, 129.9, 129.3, 128.4, 125.2, 123.2, 118.8, 108.2, 105.4, 100.4.

5-Bromo-2-(4-chloroquinolin-3-yl)phenol (4f): White solid (0.31g, 94\%), ${ }^{1} \mathrm{H}-\mathrm{NMR}\left(400 \mathrm{MHz}, \mathrm{CDCl}_{3}\right) \delta$ $8.65(\mathrm{~s}, 1 \mathrm{H}), 8.04(\mathrm{~d}, J=8.4 \mathrm{~Hz}, 1 \mathrm{H}), 7.94(\mathrm{~d}, J=8.4 \mathrm{~Hz}, 1 \mathrm{H}), 7.69(\mathrm{dd}, J=8.1,7.2 \mathrm{~Hz}, 1 \mathrm{H}), 7.51(\mathrm{dd}$, $J=8.0,7.2 \mathrm{~Hz}, 1 \mathrm{H}), 7.30(\mathrm{~s}, 1 \mathrm{H}), 7.19-7.16(\mathrm{~m}, 1 \mathrm{H}), 7.08(\mathrm{~d}, J=8.2 \mathrm{~Hz}, 1 \mathrm{H}) .{ }^{13} \mathrm{C}-\mathrm{NMR}\left(100 \mathrm{MHz} \mathrm{CDCl}_{3}\right)$ $\delta 154.2,150.5,145.9,141.4,131.4,129.7,128.2,127.4,127.2,125.0,123.5,122.7,122.5,120.7,119.5$.

5-Chloro-2-(4-chloroquinolin-3-yl)phenol (4g): White solid (0.26 g, 88\%), ${ }^{1} \mathrm{H}-\mathrm{NMR}(400 \mathrm{MHz}$, $\left.\mathrm{CD}_{3} \mathrm{OD} / \mathrm{CDCl}_{3}=2 / 3\right) \delta 8.70(\mathrm{~s}, 1 \mathrm{H}), 8.32(\mathrm{~d}, J=8.4 \mathrm{~Hz}, 1 \mathrm{H}), 8.05(\mathrm{~d}, J=8.3 \mathrm{~Hz}, 1 \mathrm{H}), 7.78(\mathrm{dd}$, $J=8.0,7.1 \mathrm{~Hz}, 1 \mathrm{H}), 7.67(\mathrm{dd}, J=8.1,7.2 \mathrm{~Hz}, 1 \mathrm{H}), 7.18(\mathrm{~d}, J=8.1 \mathrm{~Hz}, 1 \mathrm{H}), 6.98-6.93(\mathrm{~m}, 2 \mathrm{H}) .{ }^{13} \mathrm{C}-\mathrm{NMR}$ $\left(100 \mathrm{MHz}, \mathrm{CD}_{3} \mathrm{OD} / \mathrm{CDCl}_{3}=2 / 3\right) \delta 154.8,150.8,146.3,141.0,134.4,131.4,129.5,129.4,127.6,127.1,125.8$, $123.8,120.8,118.8,115.2$.

2-(4-Chloroquinolin-3-yl)-4-fluorophenol (4h): Yellow solid (0.22 g, 80\%), ${ }^{1} \mathrm{H}-\mathrm{NMR}(400 \mathrm{MHz}$, $\left.\mathrm{CD}_{3} \mathrm{OD} / \mathrm{CDCl}_{3}=2 / 3\right) \delta 8.73(\mathrm{~s}, 1 \mathrm{H}), 8.33(\mathrm{~d}, J=8.3 \mathrm{~Hz}, 1 \mathrm{H}), 8.06(\mathrm{~d}, J=8.4 \mathrm{~Hz}, 1 \mathrm{H}), 7.79(\mathrm{dd}$, 
$J=7.9,7.3 \mathrm{~Hz}, 1 \mathrm{H}), 7.68(\mathrm{dd}, J=8.0,7.2 \mathrm{~Hz}, 1 \mathrm{H}), 7.01-6.97(\mathrm{~m}, 2 \mathrm{H}), 6.93-6.90(\mathrm{~m}, 1 \mathrm{H}) .{ }^{13} \mathrm{C}-\mathrm{NMR}$ $\left(100 \mathrm{MHz}, \mathrm{CD}_{3} \mathrm{OD} / \mathrm{CDCl}_{3}=2 / 3\right) \delta 155.2\left(\mathrm{~d}, \mathrm{~J}_{\mathrm{C}-\mathrm{F}}=235.9 \mathrm{~Hz}\right), 150.7,150.1\left(\mathrm{~d}, \mathrm{~J}_{\mathrm{C}-\mathrm{F}}=1.8 \mathrm{~Hz}\right), 146.4,141.0$, $129.6,129.3,127.7,127.2,125.8,123.8,122.8\left(\mathrm{~d}, \mathrm{~J}_{\mathrm{C}-\mathrm{F}}=8.0 \mathrm{~Hz}\right), 116.6\left(\mathrm{~d}, \mathrm{~J}_{\mathrm{C}-\mathrm{F}}=23.4 \mathrm{~Hz}\right), 115.8\left(\mathrm{~d}, \mathrm{~J}_{\mathrm{C}-\mathrm{F}}=\right.$ $8.0 \mathrm{~Hz}), 115.6\left(\mathrm{~d}, \mathrm{~J}_{\mathrm{C}-\mathrm{F}}=22.7 \mathrm{~Hz}\right)$.

4-Chloro-2-(4-chloroquinolin-3-yl)phenol (4i): Yellow solid (0.28 g, 95\%), ${ }^{1} \mathrm{H}-\mathrm{NMR}\left(400 \mathrm{MHz}, \mathrm{CD}_{3} \mathrm{OD}\right) \delta$ $9.28(\mathrm{~s}, 1 \mathrm{H}), 8.67(\mathrm{~d}, J=8.5 \mathrm{~Hz}, 1 \mathrm{H}), 8.30(\mathrm{~d}, J=8.5 \mathrm{~Hz}, 1 \mathrm{H}), 8.25(\mathrm{dd}, J=8.5,6.9 \mathrm{~Hz}, 1 \mathrm{H}), 8.10(\mathrm{dd}$, $J=8.2,7.2 \mathrm{~Hz}, 1 \mathrm{H}), 7.44(\mathrm{~d}, J=2.5 \mathrm{~Hz}, 1 \mathrm{H}), 7.38(\mathrm{dd}, J=8.8,2.6 \mathrm{~Hz}, 1 \mathrm{H}), 7.00(\mathrm{~d}, J=8.8 \mathrm{~Hz}, 1 \mathrm{H})$. ${ }^{13} \mathrm{C}-\mathrm{NMR}\left(100 \mathrm{MHz}, \mathrm{CD}_{3} \mathrm{OD}\right) \delta 155.3,153.9,147.7,138.8,136.8,132.8,132.7,132.6,131.8,129.0,127.2$, $125.5,122.8,122.2,118.5$.

2-(4-Chloroquinolin-3-yl)-4-methylphenol (4j): Brown solid (0.25 g, 92\%), ${ }^{1} \mathrm{H}-\mathrm{NMR}(400 \mathrm{MHz}$, $\left.\mathrm{CD}_{3} \mathrm{OD} / \mathrm{CDCl}_{3}=1 / 4\right) \delta 8.92(\mathrm{~s}, 1 \mathrm{H}), 8.47(\mathrm{~d}, J=7.9 \mathrm{~Hz}, 1 \mathrm{H}), 8.24(\mathrm{~s}, 1 \mathrm{H}), 8.01-7.88(\mathrm{~m}, 2 \mathrm{H}), 7.13-7.08(\mathrm{~m}$, $2 \mathrm{H}), 6.87(\mathrm{~d}, J=8.0 \mathrm{~Hz}, 1 \mathrm{H}), 2.28(\mathrm{~s}, 3 \mathrm{H}) .{ }^{13} \mathrm{C}-\mathrm{NMR}\left(100 \mathrm{MHz}, \mathrm{CD}_{3} \mathrm{OD} / \mathrm{CDCl}_{3}=1 / 4\right) \delta 152.3,148.5$, 148.2, 140.6, 133.4, 132.3, 131.8, 131.2, 130.1, 129.0, 127.4, 125.5, 123.8, 120.3, 115.8, 20.0.

2-(4-Chloroquinolin-3-yl)-4-(trifluoromethoxy)phenol (4k): Yellow solid $(0.29 \mathrm{~g}, 85 \%),{ }^{1} \mathrm{H}-\mathrm{NMR}(400 \mathrm{MHz}$, $\left.\mathrm{CD}_{3} \mathrm{OD} / \mathrm{CDCl}_{3}=1 / 4\right) \delta 8.81(\mathrm{~s}, 1 \mathrm{H}), 8.31(\mathrm{~d}, J=8.2 \mathrm{~Hz}, 1 \mathrm{H}), 8.16(\mathrm{~d}, J=8.2 \mathrm{~Hz}, 1 \mathrm{H}), 7.80(\mathrm{dd}, J=8.0$, $6.7 \mathrm{~Hz}, 1 \mathrm{H}), 7.69(\mathrm{dd}, J=7.8,7.3 \mathrm{~Hz}, 1 \mathrm{H}), 7.14-7.12(\mathrm{~m}, 2 \mathrm{H}), 6.96(\mathrm{~d}, J=7.8 \mathrm{~Hz}, 1 \mathrm{H}) .{ }^{13} \mathrm{C}-\mathrm{NMR}(100 \mathrm{MHz}$, $\left.\mathrm{CD}_{3} \mathrm{OD} / \mathrm{CDCl}_{3}=1 / 4\right) \delta 150.9,147.7,142.3,141.6,138.9\left(\mathrm{~d}, \mathrm{~J}_{\mathrm{C}-\mathrm{F}}=1.6 \mathrm{~Hz}\right), 129.1,127.2,126.2,124.5,124.3$, $122.4,121.8,121.0,120.2,119.3,116.7,114.4$.

2-(4-Chloroquinolin-3-yl)benzene-1,4-diol (41): Brown solid (0.19 g, 68\%), ${ }^{1} \mathrm{H}-\mathrm{NMR}\left(400 \mathrm{MHz}\right.$, DMSO-d $\left.{ }_{6}\right)$ $\delta 9.02(\mathrm{~s}, 1 \mathrm{H}), 8.38(\mathrm{~d}, J=8.2 \mathrm{~Hz}, 1 \mathrm{H}), 8.20(\mathrm{~d}, J=8.2 \mathrm{~Hz}, 1 \mathrm{H}), 8.01(\mathrm{dd}, J=7.5,7.1 \mathrm{~Hz}, 1 \mathrm{H}), 7.90(\mathrm{dd}$, $J=7.5,7.4 \mathrm{~Hz}, 1 \mathrm{H}), 6.84(\mathrm{~d}, J=8.6 \mathrm{~Hz}, 1 \mathrm{H}), 6.77-6.74(\mathrm{~m}, 1 \mathrm{H}), 6.71(\mathrm{~d}, J=2.4 \mathrm{~Hz}, 1 \mathrm{H}) .{ }^{13} \mathrm{C}-\mathrm{NMR}$ $\left(100 \mathrm{MHz}, \mathrm{DMSO}-d_{6}\right) \delta 150.3,149.7,147.3,143.5,143.2,131.9,131.4,129.3,126.4,126.0,124.5,122.0$, 117.1, 117.0, 116.6.

3-Chloro-2-(4-chloroquinolin-3-yl)phenol (4m): Golden solid (0.27 g, 94\%), ${ }^{1} \mathrm{H}-\mathrm{NMR}(400 \mathrm{MHz}$, $\left.\mathrm{CD}_{3} \mathrm{OD} / \mathrm{CDCl}_{3}=2 / 3\right) \delta 8.62(\mathrm{~s}, 1 \mathrm{H}), 8.32(\mathrm{~d}, J=8.0 \mathrm{~Hz}, 1 \mathrm{H}), 8.07(\mathrm{~d}, J=8.4 \mathrm{~Hz}, 1 \mathrm{H}), 7.80-7.76$ $(\mathrm{m}, 1 \mathrm{H}), 7.68-7.64(\mathrm{~m}, 1 \mathrm{H}), 7.22(\mathrm{dd}, J=8.2,8.1 \mathrm{~Hz}, 1 \mathrm{H}), 7.02(\mathrm{~d}, J=7.4 \mathrm{~Hz}, 1 \mathrm{H}), 6.88(\mathrm{~d}, J=8.2 \mathrm{~Hz}, 1 \mathrm{H})$. ${ }^{13} \mathrm{C}-\mathrm{NMR}\left(100 \mathrm{MHz}, \mathrm{CD}_{3} \mathrm{OD} / \mathrm{CDCl}_{3}=2 / 3\right) \delta 162.3,155.4,150.7,146.5,142.2,133.7,129.6,127.9,127.7$, $127.0,125.7,123.8,121.5,119.4,113.2$.

2-(4-Chloro-5-methylquinolin-3-yl)phenol (4n): Yellow solid $(0.26 \mathrm{~g}, 95 \%),{ }^{1} \mathrm{H}-\mathrm{NMR}(400 \mathrm{MHz}$, $\left.\mathrm{CD}_{3} \mathrm{OD} / \mathrm{CDCl}_{3}=3 / 2\right) \delta 8.65(\mathrm{~s}, 1 \mathrm{H}), 7.95(\mathrm{~d}, J=8.3 \mathrm{~Hz}, 1 \mathrm{H}), 7.63(\mathrm{dd}, J=8.2,7.4 \mathrm{~Hz}, 1 \mathrm{H}), 7.46$ $(\mathrm{d}, J=7.3 \mathrm{~Hz}, 1 \mathrm{H}), 7.31-7.27(\mathrm{~m}, 1 \mathrm{H}), 7.21-7.19(\mathrm{~m}, 1 \mathrm{H}), 6.98-6.94(\mathrm{~m}, 2 \mathrm{H}), 3.06(\mathrm{~s}, 3 \mathrm{H}) .{ }^{13} \mathrm{C}-\mathrm{NMR}$ $\left(100 \mathrm{MHz}, \mathrm{CD}_{3} \mathrm{OD} / \mathrm{CDCl}_{3}=3 / 2\right) \delta 153.8,148.9,146.7,143.3,135.6,132.1,131.1,130.2,129.5,129.4,125.6$ (2C), 122.5, 118.7, 115.0, 25.0.

2-(4,6-Dichloroquinolin-3-yl)phenol (4o): Orange solid (0.27 g, 94\%), ${ }^{1} \mathrm{H}-\mathrm{NMR}\left(400 \mathrm{MHz}\right.$, DMSO- $\left.d_{6}\right) \delta$ $9.83(\mathrm{br} \mathrm{s}, 1 \mathrm{H}), 8.82(\mathrm{~s}, 1 \mathrm{H}), 8.26(\mathrm{~d}, J=2.3 \mathrm{~Hz}, 1 \mathrm{H}), 8.15(\mathrm{~d}, J=8.9 \mathrm{~Hz}, 1 \mathrm{H}), 7.91(\mathrm{dd}, J=9.0,2.3 \mathrm{~Hz}, 1 \mathrm{H})$, 7.34-7.27 (m, 2H), 7.01 (d, J = 7.6 Hz, 1H), 6.97-6.93 (m, 1H). ${ }^{13} \mathrm{C}-\mathrm{NMR}(100 \mathrm{MHz}$, DMSO-d 6 ) $\delta 154.8$, $152.6,145.5,138.8,133.0,131.8,131.5,131.0,130.9,130.3,126.5,122.8,122.3,119.0,115.8$.

2-(4-Chloro-6-methylquinolin-3-yl)phenol (4p): Yellow solid (0.23 g, 86\%), ${ }^{1} \mathrm{H}-\mathrm{NMR}\left(400 \mathrm{MHz}, \mathrm{DMSO}-d_{6}\right)$ $\delta 9.65(\mathrm{~s}, 1 \mathrm{H}), 8.61(\mathrm{~s}, 1 \mathrm{H}), 7.97(\mathrm{~s}, 1 \mathrm{H}), 7.93(\mathrm{~d}, J=8.5 \mathrm{~Hz}, 1 \mathrm{H}), 7.63(\mathrm{~d}, J=8.4 \mathrm{~Hz}, 1 \mathrm{H}), 7.24-7.18(\mathrm{~m}$, 2H), $6.93(\mathrm{~d}, J=8.0 \mathrm{~Hz}, 1 \mathrm{H}), 6.8-6.84(\mathrm{~m}, 1 \mathrm{H}), 2.42(\mathrm{~s}, 3 \mathrm{H}) .{ }^{13} \mathrm{C}-\mathrm{NMR}\left(100 \mathrm{MHz}, \mathrm{DMSO}-d_{6}\right) \delta 154.9$, 151.2, 145.9, 138.8, 138.0, 132.2, 131.1, 130.8, 129.9, 129.1, 125.5, 122.9, 122.6, 119.0, 115.8, 21.4.

4-Chloro-3-(2-hydroxyphenyl)quinolin-6-ol (4q): Dark-red solid (0.25 g, 91\%), ${ }^{1} \mathrm{H}-\mathrm{NMR}(400 \mathrm{MHz}$, DMSO- $\left.d_{6}\right) \delta 11.03(\mathrm{br} \mathrm{s}, 1 \mathrm{H}), 9.93(\mathrm{br} \mathrm{s}, 1 \mathrm{H}), 9.01(\mathrm{~s}, 1 \mathrm{H}), 8.17-8.16(\mathrm{~m}, 1 \mathrm{H}), 7.66-7.63(\mathrm{~m}, 2 \mathrm{H}), 7.34(\mathrm{~s}$, 2H), 7.06-6.98 (m, 2H). ${ }^{13} \mathrm{C}-\mathrm{NMR}\left(100 \mathrm{MHz}, \mathrm{DMSO}-d_{6}\right) \delta 158.8,154.8(2 \mathrm{C}), 144.5,135.2,131.5,131.1$, $131.0,130.7,128.2,121.2,119.1,115.9,105.5,99.5$. 
2-(4-Chloro-7-fluoroquinolin-3-yl)phenol (4r): Light yellow solid (0.25 g, 92\%), ${ }^{1} \mathrm{H}-\mathrm{NMR}(400 \mathrm{MHz}$, DMSO- $\left.d_{6}\right) \delta 9.78(\mathrm{~s}, 1 \mathrm{H}), 8.81(\mathrm{~s}, 1 \mathrm{H}), 8.37(\mathrm{dd}, J=9.3,6.0 \mathrm{~Hz}, 1 \mathrm{H}), 7.91(\mathrm{dd}, J=10.0,2.5 \mathrm{~Hz}, 1 \mathrm{H})$, 7.76-7.71 (m, 1H), 7.33-7.28 (m, 2H), 7.01 (d, J = 8.1 Hz, 1H), 6.97-6.93 (m, 1H). ${ }^{13} \mathrm{C}-\mathrm{NMR}(100 \mathrm{MHz}$, DMSO- $\left._{6}\right) \delta 162.6\left(\mathrm{~d}, \mathrm{~J}_{\mathrm{C}-\mathrm{F}}=247.7 \mathrm{~Hz}\right), 154.9,153.5,148.2\left(\mathrm{~d}, \mathrm{~J}_{\mathrm{C}-\mathrm{F}}=12.8 \mathrm{~Hz}\right), 139.8\left(\mathrm{~d}, \mathrm{~J}_{\mathrm{C}-\mathrm{F}}=0.8 \mathrm{~Hz}\right)$, $131.1,130.5\left(\mathrm{~d}, \mathrm{~J}_{\mathrm{C}-\mathrm{F}}=2.4 \mathrm{~Hz}\right), 130.1,127.0\left(\mathrm{~d}, \mathrm{~J}_{\mathrm{C}-\mathrm{F}}=10.1 \mathrm{~Hz}\right), 122.9,122.4,119.0,118.3\left(\mathrm{~d}, \mathrm{~J}_{\mathrm{C}-\mathrm{F}}=25.1 \mathrm{~Hz}\right)$, $115.8,112.9\left(\mathrm{~d}, \mathrm{~J}_{\mathrm{C}-\mathrm{F}}=20.4 \mathrm{~Hz}\right)$.

2-(4,7-Dichloroquinolin-3-yl)phenol (4s): Orange solid $(0.26 \mathrm{~g}, 90 \%),{ }^{1} \mathrm{H}-\mathrm{NMR}\left(400 \mathrm{MHz}, \mathrm{CD}_{3} \mathrm{OD} / \mathrm{CDCl}_{3}\right.$ $=3 / 2) \delta 8.76(\mathrm{~s}, 1 \mathrm{H}), 8.29(\mathrm{~d}, J=9.0 \mathrm{~Hz}, 1 \mathrm{H}), 8.05(\mathrm{~d}, J=2.0 \mathrm{~Hz}, 1 \mathrm{H}), 7.64(\mathrm{dd}, J=9.0,2.0 \mathrm{~Hz}, 1 \mathrm{H})$, 7.32-7.28 (m, 1H), $7.24(\mathrm{dd}, J=7.4,1.0 \mathrm{~Hz}, 1 \mathrm{H}), 6.98-6.94(\mathrm{~m}, 2 \mathrm{H}) .{ }^{13} \mathrm{C}-\mathrm{NMR}\left(100 \mathrm{MHz}, \mathrm{CD}_{3} \mathrm{OD} / \mathrm{CDCl}_{3}\right.$ $=3 / 2) \delta 156.1,154.6,148.8,143.1,137.6,133.0,132.6,131.7,130.1,128.7,127.6,126.7,123.9,120.8,117.1$.

2-(4-Chloro-7-methylquinolin-3-yl)phenol (4t): Earthy solid (0.23 g, 86\%), ${ }^{1} \mathrm{H}-\mathrm{NMR}\left(400 \mathrm{MHz}, \mathrm{DMSO}-\mathrm{d}_{6}\right)$ $\delta 9.79(\mathrm{br} \mathrm{s}, 1 \mathrm{H}), 8.80(\mathrm{~s}, 1 \mathrm{H}), 8.20(\mathrm{~d}, J=8.0 \mathrm{~Hz}, 1 \mathrm{H}), 7.93(\mathrm{~s}, 1 \mathrm{H}), 7.67(\mathrm{~d}, J=8.4 \mathrm{~Hz}, 1 \mathrm{H}), 7.33-7.27(\mathrm{~m}$, $2 \mathrm{H}), 7.01(\mathrm{~d}, J=8.0 \mathrm{~Hz}, 1 \mathrm{H}), 6.95(\mathrm{dd}, J=7.4,7.3 \mathrm{~Hz}, 1 \mathrm{H}), 2.58(\mathrm{~s}, 3 \mathrm{H}) .{ }^{13} \mathrm{C}-\mathrm{NMR}\left(100 \mathrm{MHz}, \mathrm{DMSO}-d_{6}\right)$ $\delta$ 154.9, 151.5, 146.4, 140.9, 140.5, 131.2, 130.6, 130.2, 130.0, 127.3, 123.8 (2C), 122.5, 119.0, 115.8, 21.2.

4-Chloro-3-(2-hydroxyphenyl)quinolin-7-ol (4u): Brown solid (0.24 g, 89\%), ${ }^{1} \mathrm{H}-\mathrm{NMR}\left(400 \mathrm{MHz}, \mathrm{CD}_{3} \mathrm{OD}\right)$ $\delta 8.96(\mathrm{~s}, 1 \mathrm{H}), 8.51(\mathrm{~d}, J=9.3 \mathrm{~Hz}, 1 \mathrm{H}), 7.59(\mathrm{dd}, J=9.4,2.2 \mathrm{~Hz}, 1 \mathrm{H}), 7.46(\mathrm{~d}, J=2.2 \mathrm{~Hz}, 1 \mathrm{H}), 7.40-7.34$ $(\mathrm{m}, 2 \mathrm{H}), 7.04-7.00(\mathrm{~m}, 2 \mathrm{H}) .{ }^{13} \mathrm{C}-\mathrm{NMR}\left(100 \mathrm{MHz}, \mathrm{CD}_{3} \mathrm{OD}\right) \delta 165.4,156.4,152.6,146.7,142.1,132.4(2 \mathrm{C})$, $130.6,129.2,124.9,123.5,121.8,120.8,116.9,103.5$.

2-(4-Chloro-8-methylquinolin-3-yl)phenol (4v): Yellow solid (0.25 g, 91\%), ${ }^{1} \mathrm{H}-\mathrm{NMR}\left(400 \mathrm{MHz}, \mathrm{DMSO}-d_{6}\right)$ $\delta 9.74(\mathrm{br} \mathrm{s}, 1 \mathrm{H}), 8.80(\mathrm{~s}, 1 \mathrm{H}), 8.13(\mathrm{~d}, J=8.0 \mathrm{~Hz}, 1 \mathrm{H}), 7.73(\mathrm{~d}, J=6.8 \mathrm{~Hz}, 1 \mathrm{H}), 7.68-7.64(\mathrm{~m}, 1 \mathrm{H}), 7.33-7.26$ $(\mathrm{m}, 2 \mathrm{H}), 7.02(\mathrm{~d}, J=7.8 \mathrm{~Hz}, 1 \mathrm{H}), 6.97-6.93(\mathrm{~m}, 1 \mathrm{H}), 2.77(\mathrm{~s}, 3 \mathrm{H}) .{ }^{13} \mathrm{C}-\mathrm{NMR}\left(100 \mathrm{MHz}, \mathrm{DMSO}-d_{6}\right) \delta 154.9$, $150.9,146.1,140.0,137.0,131.1,130.7,130.2,130.0,127.8,125.6,122.9,121.9,119.0,115.8,17.9$.

2-(7-Bromo-4-chloroquinolin-3-yl)benzene-1,4-diol (4w): Yellow solid $(0.34 \mathrm{~g}, 97 \%),{ }^{1} \mathrm{H}-\mathrm{NMR}(400 \mathrm{MHz}$, $\left.\mathrm{CD}_{3} \mathrm{OD}\right) \delta 8.74(\mathrm{~s}, 1 \mathrm{H}), 8.26-8.24(\mathrm{~m}, 2 \mathrm{H}), 7.82(\mathrm{dd}, J=9.0,1.9 \mathrm{~Hz}, 1 \mathrm{H}), 6.83-6.76(\mathrm{~m}, 2 \mathrm{H}), 6.72(\mathrm{~d}$, $J=2.7 \mathrm{~Hz}, 1 \mathrm{H}) .{ }^{13} \mathrm{C}-\mathrm{NMR}\left(100 \mathrm{MHz}, \mathrm{CD}_{3} \mathrm{OD}\right) \delta 154.6,151.3,149.0$ (2C), 142.7, 133.2, 132.5, 131.9, 127.4, $126.7,125.5,124.4,118.3,118.2,117.9$.

2-(4,7-Dichloroquinolin-3-yl)benzene-1,4-diol (4x): Brick-red solid (0.28 g, 91\%), ${ }^{1} \mathrm{H}-\mathrm{NMR}(400 \mathrm{MHz}$, DMSO- $\left.d_{6}\right) \delta 8.83(\mathrm{~s}, 1 \mathrm{H}), 8.31(\mathrm{~d}, J=9.0 \mathrm{~Hz}, 1 \mathrm{H}), 8.20(\mathrm{~d}, J=1.8 \mathrm{~Hz}, 1 \mathrm{H}), 7.84(\mathrm{dd}, J=9.0,1.8 \mathrm{~Hz}, 1 \mathrm{H})$, $6.83(\mathrm{~d}, J=8.7 \mathrm{~Hz}, 1 \mathrm{H}), 6.74(\mathrm{dd}, J=8.6,2.7 \mathrm{~Hz}, 1 \mathrm{H}), 6.68(\mathrm{~d}, J=2.7 \mathrm{~Hz}, 1 \mathrm{H}) .{ }^{13} \mathrm{C}-\mathrm{NMR}(100 \mathrm{MHz}$, DMSO- $\left.d_{6}\right) \delta 153.3,149.7,147.3,147.0,140.0,135.0,131.5,128.9,127.6,126.3,124.5,122.5,117.0,116.9$, 116.6.

\subsubsection{General Procedures for the Synthesis of Benzofuro[3,2-c]Quionlines $\mathbf{2 a}-\mathbf{2} \mathbf{x}$}

To a solution of the 2-(4-chloroquinolin-3-yl)phenol (1 equiv.) in DMF (5 mL), KOt-Bu (2 equiv.) was added in one portion. The reaction mixture was first stirred at $25^{\circ} \mathrm{C}$ for $0.5 \mathrm{~h}$, then stirred at 60 ${ }^{\circ} \mathrm{C}$ for $2 \mathrm{~h}$. The mixture was poured into ice water. The organic phase was separated and the water phase was extracted with ethyl acetate three times $(3 \times 20 \mathrm{~mL})$. The combined organic phases were dried over anhydrous $\mathrm{Na}_{2} \mathrm{SO}_{4}$. Removal of the solvent was done in vacuo, and the crude mixture was further purified using column chromatography over silica gel using petroleum ether/ethyl acetate $(15: 1)$ as eluent.

Benzofuro[3,2-c]quinoline (2a): White solid (0.19 g, 88\%), m.p. $130-132{ }^{\circ} \mathrm{C} .{ }^{1} \mathrm{H}-\mathrm{NMR}\left(400 \mathrm{MHz}, \mathrm{CDCl}_{3}\right) \delta$ $9.48(\mathrm{~s}, 1 \mathrm{H}), 8.40(\mathrm{~d}, J=8.1 \mathrm{~Hz}, 1 \mathrm{H}), 8.26(\mathrm{~d}, J=8.4 \mathrm{~Hz}, 1 \mathrm{H}), 8.08(\mathrm{~d}, J=7.6 \mathrm{~Hz}, 1 \mathrm{H}), 7.80-7.73(\mathrm{~m}, 2 \mathrm{H})$, $7.69(\mathrm{dd}, J=7.6,7.4 \mathrm{~Hz}, 1 \mathrm{H}), 7.54(\mathrm{dd}, J=7.8,7.4 \mathrm{~Hz}, 1 \mathrm{H}), 7.46(\mathrm{dd}, J=7.4,7.3 \mathrm{~Hz}, 1 \mathrm{H}) .{ }^{13} \mathrm{C}-\mathrm{NMR}$ $\left(100 \mathrm{MHz}, \mathrm{CDCl}_{3}\right) \delta 156.4,154.9,146.4,143.4,128.8,128.2,126.2,126.0,123.0,121.6,119.8,119.6,116.1$, 115.3, 111.1; HRMS (ESI): calcd. for $\mathrm{C}_{15} \mathrm{H}_{10} \mathrm{NO}[\mathrm{M}+\mathrm{H}]^{+}$220.0757; found 220.0759.

6-Methylbenzofuro[3,2-c]quinoline (2b): White solid (0.15 g, 85\%), m.p. 139-141 ${ }^{\circ} \mathrm{C} .{ }^{1} \mathrm{H}-\mathrm{NMR}(400 \mathrm{MHz}$, $\left.\mathrm{CDCl}_{3}\right) \delta 9.48-9.46(\mathrm{~m}, 1 \mathrm{H}), 8.45(\mathrm{dd}, J=7.8,6.7 \mathrm{~Hz}, 1 \mathrm{H}), 8.26(\mathrm{~d}, J=8.3 \mathrm{~Hz}, 1 \mathrm{H}), 7.91(\mathrm{dd}, J=8.6$, 
$6.8 \mathrm{~Hz}, 1 \mathrm{H}), 7.80-7.76(\mathrm{~m}, 1 \mathrm{H}), 7.69(\mathrm{dd}, J=8.0,6.9 \mathrm{~Hz}, 1 \mathrm{H}), 7.38-7.34(\mathrm{~m}, 2 \mathrm{H}), 2.70(\mathrm{~s}, 3 \mathrm{H}) .{ }^{13} \mathrm{C}-\mathrm{NMR}$ $\left(100 \mathrm{MHz} \mathrm{CDCl}_{3}\right) \delta 156.2,153.9,146.3,143.6,128.8,128.1,127.2,125.8,123.0,121.4,121.1,119.8,116.9$, 116.2, 115.7, 14.2; HRMS (ESI): calcd. for $\mathrm{C}_{16} \mathrm{H}_{12} \mathrm{NO}[\mathrm{M}+\mathrm{H}]^{+}$234.0913; found 234.0906.

6-Fluorobenzofuro[3,2-c]quinoline (2c): White solid (0.17 g, 82\%), m.p. $154-157^{\circ} \mathrm{C} .{ }^{1} \mathrm{H}-\mathrm{NMR}(400 \mathrm{MHz}$, $\left.\mathrm{CDCl}_{3}\right) \delta 9.47(\mathrm{~s}, 1 \mathrm{H}), 8.46(\mathrm{~d}, J=8.0 \mathrm{~Hz}, 1 \mathrm{H}), 8.27(\mathrm{~d}, J=8.5 \mathrm{~Hz}, 1 \mathrm{H}), 7.85(\mathrm{~d}, J=7.7 \mathrm{~Hz}, 1 \mathrm{H}), 7.84-7.79$ $(\mathrm{m}, 1 \mathrm{H}), 7.72(\mathrm{dd}, J=7.4,7.2 \mathrm{~Hz}, 1 \mathrm{H}), 7.40(\mathrm{ddd}, J=8.0,7.9,4.3 \mathrm{~Hz}, 1 \mathrm{H}), 7.31-7.27(\mathrm{~m}, 1 \mathrm{H}) .{ }^{13} \mathrm{C}-\mathrm{NMR}$ $\left(100 \mathrm{MHz}, \mathrm{CDCl}_{3}\right) \delta 156.8,147.3\left(\mathrm{~d}, J_{\mathrm{C}-\mathrm{F}}=249.5 \mathrm{~Hz}\right), 146.7,143.3,141.7\left(\mathrm{~d}, J_{\mathrm{C}-\mathrm{F}}=11.3 \mathrm{~Hz}\right), 128.8,128.7$, $126.3,125.2\left(\mathrm{~d}, J_{\mathrm{C}-\mathrm{F}}=2.6 \mathrm{~Hz}\right), 123.8\left(\mathrm{~d}, J_{\mathrm{C}-\mathrm{F}}=5.8 \mathrm{~Hz}\right), 119.8,116.0,115.1\left(\mathrm{~d}, J_{\mathrm{C}-\mathrm{F}}=4.0 \mathrm{~Hz}\right), 115.0(\mathrm{~d}$, $\left.J_{\mathrm{C}-\mathrm{F}}=2.2 \mathrm{~Hz}\right), 112.7\left(\mathrm{~d}, J_{\mathrm{C}-\mathrm{F}}=16.1 \mathrm{~Hz}\right)$; HRMS (ESI): calcd. for $\mathrm{C}_{15} \mathrm{H}_{9} \mathrm{FNO}[\mathrm{M}+\mathrm{H}]^{+} 238.0663$; found 238.0667 .

5-Methylbenzofuro[3,2-c]quinoline (2d): White solid (0.17 g, 92\%), m.p. $146-149{ }^{\circ} \mathrm{C} .{ }^{1} \mathrm{H}-\mathrm{NMR}$ $\left(400 \mathrm{MHz}, \mathrm{CDCl}_{3}\right) \delta 9.40(\mathrm{~s}, 1 \mathrm{H}), 8.34(\mathrm{~d}, J=8.0 \mathrm{~Hz}, 1 \mathrm{H}), 8.23(\mathrm{~d}, J=8.4 \mathrm{~Hz}, 1 \mathrm{H}), 7.88(\mathrm{~d}, J=7.8 \mathrm{~Hz}, 1 \mathrm{H})$, $7.74(\mathrm{dd}, J=7.3,7.0 \mathrm{~Hz}, 1 \mathrm{H}), 7.64(\mathrm{dd}, J=7.8,7.1 \mathrm{~Hz}, 1 \mathrm{H}), 7.48(\mathrm{~s}, 1 \mathrm{H}), 7.23(\mathrm{~d}, J=7.8 \mathrm{~Hz}, 1 \mathrm{H}), 2.53$ (s, 3H). ${ }^{13} \mathrm{C}-\mathrm{NMR}\left(100 \mathrm{MHz}, \mathrm{CDCl}_{3}\right) \delta 156.2,155.3,146.0,143.1,136.8,128.7,127.9,125.8,124.2,119.6$, 119.0, 116.1, 115.3, 111.2, 20.9; HRMS (ESI): calcd. for $\mathrm{C}_{16} \mathrm{H}_{12} \mathrm{NO}[\mathrm{M}+\mathrm{H}]^{+}$234.0913; found 234.0907.

Benzofuro[3,2-c]quinolin-5-ol (2e): Earthy solid (0.03 g, 12\%), m.p. $>250{ }^{\circ} \mathrm{C} .{ }^{1} \mathrm{H}-\mathrm{NMR}(400 \mathrm{MHz}$, $\left.\mathrm{CD}_{3} \mathrm{OD} / \mathrm{CDCl}_{3}=3 / 2\right) \delta 9.30(\mathrm{~s}, 1 \mathrm{H}), 8.33(\mathrm{~d}, J=8.1 \mathrm{~Hz}, 1 \mathrm{H}), 8.13(\mathrm{~d}, J=8.4 \mathrm{~Hz}, 1 \mathrm{H}), 7.88(\mathrm{~d}, J=8.4 \mathrm{~Hz}$, $1 \mathrm{H}), 7.74(\mathrm{dd}, J=8.3,7.0 \mathrm{~Hz}, 1 \mathrm{H}), 7.67(\mathrm{dd}, J=7.4,7.3 \mathrm{~Hz}, \mathrm{H}), 7.17(\mathrm{~s}, 1 \mathrm{H}), 6.97(\mathrm{~d}, J=8.4 \mathrm{~Hz}, 1 \mathrm{H})$. ${ }^{13} \mathrm{C}-\mathrm{NMR}\left(100 \mathrm{MHz}, \mathrm{CD}_{3} \mathrm{OD} / \mathrm{CDCl}_{3}=3 / 2\right) \delta 158.0,157.6,157.2,145.7,143.3,128.9,128.3,127.0,120.8$, 120.4, 117.0, 116.9, 114.2, 113.1, 98.6; HRMS (ESI): calcd. for $\mathrm{C}_{15} \mathrm{H}_{10} \mathrm{NO}_{2}[\mathrm{M}+\mathrm{H}]^{+}$236.0706; found 236.0707 .

5-Bromobenzofuro[3,2-c]quinoline (2f): White solid (0.24 g, 85\%), m.p. $195-196{ }^{\circ} \mathrm{C} .{ }^{1} \mathrm{H}-\mathrm{NMR}(400 \mathrm{MHz}$, $\left.\mathrm{CDCl}_{3}\right) \delta 9.46(\mathrm{~s}, 1 \mathrm{H}), 8.40(\mathrm{~d}, J=8.0 \mathrm{~Hz}, 1 \mathrm{H}), 8.27(\mathrm{~d}, J=8.4 \mathrm{~Hz}, 1 \mathrm{H}), 7.96-7.93(\mathrm{~m}, 2 \mathrm{H}), 7.81$ (ddd, $J=8.3,7.0,1.2 \mathrm{~Hz}, 1 \mathrm{H}), 7.71(\mathrm{ddd}, J=8.0,7.1,1.1 \mathrm{~Hz}, 1 \mathrm{H}), 7.61(\mathrm{~d}, J=8.2 \mathrm{~Hz}, 1 \mathrm{H}) .{ }^{13} \mathrm{C}-\mathrm{NMR}(100 \mathrm{MHz}$, $\left.\mathrm{CDCl}_{3}\right) \delta 156.7,155.1,146.5,143.1,128.9,128.6,126.5,126.3,120.8,120.5,119.8,119.4,116.0,114.7(2 \mathrm{C})$; HRMS (ESI): calcd. for $\mathrm{C}_{15} \mathrm{H}_{9} \mathrm{BrNO}[\mathrm{M}+\mathrm{H}]^{+}$297.9862; found 297.9869 .

5-Chlorobenzofuro[3,2-c]quinoline (2g): White solid (0.17 g, 75\%), m.p. $194-195{ }^{\circ} \mathrm{C} .{ }^{1} \mathrm{H}-\mathrm{NMR}(400 \mathrm{MHz}$, $\left.\mathrm{CDCl}_{3}\right) \delta 9.45(\mathrm{~s}, 1 \mathrm{H}), 8.39(\mathrm{~d}, J=8.0 \mathrm{~Hz}, 1 \mathrm{H}), 8.27(\mathrm{~d}, J=8.4 \mathrm{~Hz}, 1 \mathrm{H}), 8.00(\mathrm{~d}, J=8.3 \mathrm{~Hz}, 1 \mathrm{H}), 7.81$ $(\mathrm{ddd}, J=8.3,7.0,0.4 \mathrm{~Hz}, 1 \mathrm{H}), 7.76(\mathrm{~s}, 1 \mathrm{H}), 7.71(\mathrm{ddd}, J=8.0,7.1,0.7 \mathrm{~Hz}, 1 \mathrm{H}), 7.46(\mathrm{~d}, J=8.3 \mathrm{~Hz}, 1 \mathrm{H})$. ${ }^{13} \mathrm{C}-\mathrm{NMR}\left(100 \mathrm{MHz}, \mathrm{CDCl}_{3}\right) \delta 156.8,155.0,146.4,143.1,131.9,128.9,128.6,126.2,123.8,120.4,120.1$, 119.7, 116.0, 114.6, 111.8; HRMS (ESI): calcd. for $\mathrm{C}_{15} \mathrm{H}_{9} \mathrm{ClNO}[\mathrm{M}+\mathrm{H}]^{+}$254.0367; found 254.0362.

4-Fluorobenzofuro[3,2-c]quinoline (2h): White solid (0.17 g, 89 \%), m.p. 187-188 ${ }^{\circ} \mathrm{C} .{ }^{1} \mathrm{H}-\mathrm{NMR}(400 \mathrm{MHz}$, $\left.\mathrm{CDCl}_{3}\right) \delta 9.42(\mathrm{~s}, 1 \mathrm{H}), 8.38(\mathrm{~d}, J=8.2 \mathrm{~Hz}, 1 \mathrm{H}), 8.26(\mathrm{~d}, J=8.4 \mathrm{~Hz}, 1 \mathrm{H}), 7.80(\mathrm{dd}, J=8.2,7.1 \mathrm{~Hz}, 1 \mathrm{H})$, 7.74-7.66 (m, 3H), 7.26-7.22 (m, 1H). ${ }^{13} \mathrm{C}-\mathrm{NMR}\left(100 \mathrm{MHz}, \mathrm{CDCl}_{3}\right) \delta 158.7\left(\mathrm{~d}, \mathrm{~J}_{\mathrm{C}-\mathrm{F}}=239.8 \mathrm{~Hz}\right), 157.6$, $150.9,146.5,143.3,128.9,128.6,126.2,122.6\left(\mathrm{~d}, J_{\mathrm{C}-\mathrm{F}}=10.6 \mathrm{~Hz}\right), 119.8,116.0,115.1\left(\mathrm{~d}, J_{\mathrm{C}-\mathrm{F}}=3.7 \mathrm{~Hz}\right), 113.7$ $\left(\mathrm{d}, J_{\mathrm{C}-\mathrm{F}}=25.8 \mathrm{~Hz}\right), 111.9\left(\mathrm{~d}, J_{\mathrm{C}-\mathrm{F}}=9.4 \mathrm{~Hz}\right), 105.7\left(\mathrm{~d}, J_{\mathrm{C}-\mathrm{F}}=25.5 \mathrm{~Hz}\right)$; HRMS (ESI): calcd. for $\mathrm{C}_{15} \mathrm{H}_{9} \mathrm{FNO}$ $[\mathrm{M}+\mathrm{H}]^{+}$238.0663; found 238.0664.

4-Chlorobenzofuro[3,2-c]quinoline (2i): White solid (0.21 g, 86\%), m.p. $181-182{ }^{\circ} \mathrm{C} .{ }^{1} \mathrm{H}-\mathrm{NMR}(400 \mathrm{MHz}$, $\left.\mathrm{CDCl}_{3}\right) \delta 9.43(\mathrm{~s}, 1 \mathrm{H}), 8.38(\mathrm{~d}, J=8.1 \mathrm{~Hz}, 1 \mathrm{H}), 8.26(\mathrm{~d}, J=8.4 \mathrm{~Hz}, 1 \mathrm{H}), 8.05(\mathrm{~d}, J=1.7 \mathrm{~Hz}, 1 \mathrm{H}), 7.80$ $(\mathrm{dd}, J=8.2,7.1 \mathrm{~Hz}, 1 \mathrm{H}), 7.70(\mathrm{dd}, J=7.7,7.4 \mathrm{~Hz}, 1 \mathrm{H}), 7.66(\mathrm{~d}, J=8.8 \mathrm{~Hz}, 1 \mathrm{H}), 7.49(\mathrm{dd}, J=8.8,1.9 \mathrm{~Hz}$, 1H). ${ }^{13} \mathrm{C}-\mathrm{NMR}\left(100 \mathrm{MHz}, \mathrm{CDCl}_{3}\right) \delta 157.2,153.2,146.6,143.2,128.9,128.7$ (2C), 126.3, 126.2, 123.1, 119.8, 119.4, 116.0, 114.5, 112.1; HRMS (ESI): calcd. for $\mathrm{C}_{15} \mathrm{H}_{9} \mathrm{ClNO}[\mathrm{M}+\mathrm{H}]^{+}$254.0367; found 254.0361.

4-Methylbenzofuro[3,2-c]quinoline (2j): Yellow solid (0.20 g, 94\%), m.p. $149-150{ }^{\circ} \mathrm{C} .{ }^{1} \mathrm{H}-\mathrm{NMR}(400 \mathrm{MHz}$, $\left.\mathrm{CDCl}_{3}\right) \delta 9.45(\mathrm{~s}, 1 \mathrm{H}), 8.40-8.38(\mathrm{~m}, 1 \mathrm{H}), 8.25(\mathrm{~d}, J=8.4 \mathrm{~Hz}, 1 \mathrm{H}), 7.87(\mathrm{~s}, 1 \mathrm{H}), 7.79-7.75(\mathrm{~m}, 1 \mathrm{H}), 7.70-7.66$ $(\mathrm{m}, 1 \mathrm{H}), 7.61(\mathrm{~d}, J=8.4 \mathrm{~Hz}, 1 \mathrm{H}), 7.34-7.32(\mathrm{~m}, 1 \mathrm{H}), 2.55(\mathrm{~s}, 3 \mathrm{H}) .{ }^{13} \mathrm{C}-\mathrm{NMR}\left(100 \mathrm{MHz}, \mathrm{CDCl}_{3}\right) \delta 157.7$, 154.4, 147.3, 144.4, 133.8, 129.8, 129.2, 128.3, 126.9, 122.7, 120.8, 120.5, 117.3, 116.3, 111.6, 21.4; HRMS (ESI): calcd. for $\mathrm{C}_{16} \mathrm{H}_{12} \mathrm{NO}[\mathrm{M}+\mathrm{H}]^{+}$234.0913; found 234.0916. 
4-(Trifluoromethoxy)benzofuro[3,2-c]quinoline (2k): White solid (0.16 g, 62\%), m.p. $143-144{ }^{\circ} \mathrm{C} .{ }^{1} \mathrm{H}-\mathrm{NMR}$ $\left(400 \mathrm{MHz}, \mathrm{CDCl}_{3}\right) \delta 9.45(\mathrm{~s}, 1 \mathrm{H}), 8.40-8.38(\mathrm{~m}, 1 \mathrm{H}), 8.27(\mathrm{~d}, J=8.4 \mathrm{~Hz}, 1 \mathrm{H}), 7.94(\mathrm{~d}, J=1.0 \mathrm{~Hz}, 1 \mathrm{H})$, 7.84-7.79 (m, 1H), 7.75-7.69 (m, 2H), $7.40(\mathrm{dd}, J=8.9,1.6 \mathrm{~Hz}, 1 \mathrm{H}) .{ }^{13} \mathrm{C}-\mathrm{NMR}\left(100 \mathrm{MHz}, \mathrm{CDCl}_{3}\right) \delta$ 157.6, 152.8, 146.6, $144.7\left(\mathrm{~d}, J_{\mathrm{C}-\mathrm{F}}=2.1 \mathrm{~Hz}\right), 143.2,129.0,128.8,126.3,122.7,119.8,119.7,119.6\left(\mathrm{q}, J_{\mathrm{C}-\mathrm{F}}\right.$ $=255.5 \mathrm{~Hz}), 115.9,114.8,112.5,112.0 .{ }^{19} \mathrm{~F} \mathrm{NMR}\left(376 \mathrm{MHz}, \mathrm{CDCl}_{3}\right): \delta-58.1$. HRMS (ESI): calcd. for $\mathrm{C}_{16} \mathrm{H}_{9} \mathrm{~F}_{3} \mathrm{NO}_{2}[\mathrm{M}+\mathrm{H}]^{+}$304.0580; found 304.0584.

Benzofuro[3,2-c]quinolin-4-ol (21): Light yellow solid (0.04 g, 23\%), m.p. $>250{ }^{\circ} \mathrm{C} .{ }^{1} \mathrm{H}-\mathrm{NMR}(400 \mathrm{MHz}$, $\left.\mathrm{CD}_{3} \mathrm{OD} / \mathrm{CDCl}_{3}=3 / 2\right) \delta 9.30(\mathrm{~s}, 1 \mathrm{H}), 8.36(\mathrm{~d}, J=7.9 \mathrm{~Hz}, 1 \mathrm{H}), 8.14(\mathrm{~d}, J=8.4 \mathrm{~Hz}, 1 \mathrm{H}), 7.76(\mathrm{dd}, J=8.4$, $8.2 \mathrm{~Hz}, 1 \mathrm{H}), 7.68(\mathrm{dd}, J=7.7,7.3 \mathrm{~Hz}, 1 \mathrm{H}), 7.55(\mathrm{~d}, J=8.8 \mathrm{~Hz}, 1 \mathrm{H}), 7.46(\mathrm{~s}, 1 \mathrm{H}), 7.03(\mathrm{dd}, J=8.9,2.5 \mathrm{~Hz}$, 1H). ${ }^{13} \mathrm{C}-\mathrm{NMR}\left(100 \mathrm{MHz}, \mathrm{CD}_{3} \mathrm{OD} / \mathrm{CDCl}_{3}=3 / 2\right) \delta 157.4,153.3,149.5,145.5,143.2,128.8,127.6,126.4$, 122.2, 120.0, 116.4, 115.9, 115.1, 111.6, 104.7; HRMS (ESI): calcd. for $\mathrm{C}_{15} \mathrm{H}_{10} \mathrm{NO}_{2}[\mathrm{M}+\mathrm{H}]^{+}$236.0706; found 236.0710 .

3-Chlorobenzofuro[3,2-c]quinoline (2m): White solid (0.10 g, 42\%), m.p. 160-162 ${ }^{\circ} \mathrm{C} .{ }^{1} \mathrm{H}-\mathrm{NMR}(400 \mathrm{MHz}$, $\left.\mathrm{CDCl}_{3}\right) \delta 9.79(\mathrm{~s}, 1 \mathrm{H}), 8.40-8.38(\mathrm{~m}, 1 \mathrm{H}), 8.28(\mathrm{~d}, J=8.4 \mathrm{~Hz}, 1 \mathrm{H}), 7.83-7.79(\mathrm{~m}, 1 \mathrm{H}), 7.72-7.68(\mathrm{~m}, 1 \mathrm{H})$, $7.65(\mathrm{dd}, J=6.7,2.3 \mathrm{~Hz}, 1 \mathrm{H}), 7.48-7.43(\mathrm{~m}, 2 \mathrm{H}) .{ }^{13} \mathrm{C}-\mathrm{NMR}\left(100 \mathrm{MHz}, \mathrm{CDCl}_{3}\right) \delta 156.5,155.2,146.4$, 144.5, 128.9, 128.7, 127.0, 126.6, 126.1, 123.5, 120.7, 119.8, 115.7, 114.5, 109.4; HRMS (ESI): calcd. for $\mathrm{C}_{15} \mathrm{H}_{9} \mathrm{ClNO}[\mathrm{M}+\mathrm{H}]^{+}$254.0367; found 254.0348.

7-Methylbenzofuro[3,2-c]quinoline (2n): Light yellow solid (0.19 g, 85\%), m.p. $146-147{ }^{\circ} \mathrm{C} .{ }^{1} \mathrm{H}-\mathrm{NMR}$ $\left(400 \mathrm{MHz}, \mathrm{CDCl}_{3}\right) \delta 9.46(\mathrm{~s}, 1 \mathrm{H}), 8.11-8.09(\mathrm{~m}, 2 \mathrm{H}), 7.75(\mathrm{~d}, J=8.1 \mathrm{~Hz}, 1 \mathrm{H}), 7.64(\mathrm{dd}, J=8.0,7.6 \mathrm{~Hz}$, $1 \mathrm{H}), 7.54(\mathrm{dd}, J=8.2,7.1 \mathrm{~Hz}, 1 \mathrm{H}), 7.49-7.44(\mathrm{~m}, 2 \mathrm{H}), 3.12(\mathrm{~s}, 3 \mathrm{H}) .{ }^{13} \mathrm{C}-\mathrm{NMR}\left(100 \mathrm{MHz}, \mathrm{CDCl}_{3}\right) \delta 158.4$, 155.8, 148.4, 144.1, 133.6, 128.9, 128.3, 127.6, 127.0, 124.0, 122.1, 120.4, 117.3, 116.6, 112.1, 22.4; HRMS (ESI): calcd. for $\mathrm{C}_{16} \mathrm{H}_{12} \mathrm{NO}[\mathrm{M}+\mathrm{H}]^{+} 234.0913$; found 234.0914 .

8-Chlorobenzofuro[3,2-c]quinoline (2o): White solid (0.22 g, 91\%), m.p. $168-169{ }^{\circ} \mathrm{C} .{ }^{1} \mathrm{H}-\mathrm{NMR}(400 \mathrm{MHz}$, $\left.\mathrm{CDCl}_{3}\right) \delta 9.42(\mathrm{~s}, 1 \mathrm{H}), 8.32(\mathrm{~d}, J=2.3 \mathrm{~Hz}, 1 \mathrm{H}), 8.16(\mathrm{~d}, J=9.0 \mathrm{~Hz}, 1 \mathrm{H}), 8.07-8.05(\mathrm{~m}, 1 \mathrm{H}), 7.72(\mathrm{~d}$, $J=8.2 \mathrm{~Hz}, 1 \mathrm{H}), 7.67(\mathrm{dd}, J=9.0,2.4 \mathrm{~Hz}, 1 \mathrm{H}), 7.57-7.53(\mathrm{~m}, 1 \mathrm{H}), 7.47(\mathrm{ddd}, J=7.6,7.5,1.0 \mathrm{~Hz}, 1 \mathrm{H})$. ${ }^{13} \mathrm{C}-\mathrm{NMR}\left(100 \mathrm{MHz}, \mathrm{CDCl}_{3}\right) \delta$ 155.3, 155.0, 144.5, 143.5, 131.9, 130.4, 129.0, 126.6, 123.2, 121.3, 119.7, 118.8, 116.7, 115.9, 111.2; HRMS (ESI): calcd. for $\mathrm{C}_{15} \mathrm{H}_{9} \mathrm{CINO}[\mathrm{M}+\mathrm{H}]^{+}$254.0367; found 254.0363.

8-Methylbenzofuro[3,2-c]quinoline (2p): White solid (0.17 g, 83\%), m.p. $153-156{ }^{\circ} \mathrm{C} .{ }^{1} \mathrm{H}-\mathrm{NMR}(400 \mathrm{MHz}$, $\left.\mathrm{CDCl}_{3}\right) \delta 9.41(\mathrm{~s}, 1 \mathrm{H}), 8.17(\mathrm{br} \mathrm{s}, 1 \mathrm{H}), 8.15(\mathrm{~d}, J=8.6 \mathrm{~Hz}, 1 \mathrm{H}), 8.09-8.07(\mathrm{~m}, 1 \mathrm{H}), 7.74(\mathrm{~d}, J=8.2 \mathrm{~Hz}$, $1 \mathrm{H}), 7.61(\mathrm{dd}, J=8.6,1.9 \mathrm{~Hz}, 1 \mathrm{H}), 7.56-7.51(\mathrm{~m}, 1 \mathrm{H}), 7.46(\mathrm{ddd}, J=7.6,7.4,0.9 \mathrm{~Hz}, 1 \mathrm{H}), 2.63(\mathrm{~s}, 3 \mathrm{H})$. ${ }^{13} \mathrm{C}-\mathrm{NMR}\left(100 \mathrm{MHz}, \mathrm{CDCl}_{3}\right) \delta 156.1,154.9,145.0,142.4,136.1,130.5,128.5,126.1,122.9,121.8,119.6$, 118.6, 116.0, 115.2, 111.0, 20.8. HRMS (ESI): calcd. for $\mathrm{C}_{16} \mathrm{H}_{12} \mathrm{NO}[\mathrm{M}+\mathrm{H}]^{+}$234.0913; found 234.0919.

Benzofuro[3,2-clquinolin-8-ol (2q): Yellow solid (0.03 g, 13\%), m.p. $>250{ }^{\circ} \mathrm{C} .{ }^{1} \mathrm{H}-\mathrm{NMR}(400 \mathrm{MHz}$, DMSO- $\left.d_{6}\right) \delta 10.41(\mathrm{~s}, 1 \mathrm{H}), 9.44(\mathrm{~s}, 1 \mathrm{H}), 8.30(\mathrm{~d}, J=7.6 \mathrm{~Hz}, 1 \mathrm{H}), 8.08(\mathrm{~d}, J=9.1 \mathrm{~Hz}, 1 \mathrm{H}), 7.92(\mathrm{~d}, J=8.2 \mathrm{~Hz}$, $1 \mathrm{H}), 7.61(\mathrm{dd}, J=7.9,7.5 \mathrm{~Hz}, 1 \mathrm{H}), 7.55-7.50(\mathrm{~m}, 2 \mathrm{H}), 7.39(\mathrm{dd}, J=9.1,2.3 \mathrm{~Hz}, 1 \mathrm{H}) .{ }^{13} \mathrm{C}-\mathrm{NMR}(100 \mathrm{MHz}$, DMSO- $\left.d_{6}\right) \delta 156.4,155.5,155.2,142.0,141.3,131.3,127.5,124.2,122.3,121.6,121.3,117.5,115.7,112.1$, 101.3; HRMS (ESI): calcd. for $\mathrm{C}_{15} \mathrm{H}_{10} \mathrm{NO}_{2}[\mathrm{M}+\mathrm{H}]^{+}$236.0706; found 236.0715.

9-Fluorobenzofuro[3,2-c]quinoline (2r): White solid (0.17 g, 77\%), m.p. $150-151{ }^{\circ} \mathrm{C} .{ }^{1} \mathrm{H}-\mathrm{NMR}(400 \mathrm{MHz}$, $\left.\mathrm{CDCl}_{3}\right) \delta 9.47(\mathrm{~s}, 1 \mathrm{H}), 8.39(\mathrm{dd}, J=9.0,6.0 \mathrm{~Hz}, 1 \mathrm{H}), 8.07(\mathrm{~d}, J=7.6 \mathrm{~Hz}, 1 \mathrm{H}), 7.89(\mathrm{dd}, J=10.3,2.4 \mathrm{~Hz}$, $1 \mathrm{H}), 7.73(\mathrm{~d}, J=8.2 \mathrm{~Hz}, 1 \mathrm{H}), 7.54(\mathrm{dd}, J=7.7,7.5 \mathrm{~Hz}, 1 \mathrm{H}), 7.50-7.46(\mathrm{~m}, 2 \mathrm{H}) .{ }^{13} \mathrm{C}-\mathrm{NMR}(100 \mathrm{MHz}$, $\left.\mathrm{CDCl}_{3}\right) \delta 161.9\left(\mathrm{~d}, J_{\mathrm{C}-\mathrm{F}}=248.2 \mathrm{~Hz}\right), 156.5\left(\mathrm{~d}, J_{\mathrm{C}-\mathrm{F}}=1.0 \mathrm{~Hz}\right), 154.8,147.4\left(\mathrm{~d}, J_{\mathrm{C}-\mathrm{F}}=12.4 \mathrm{~Hz}\right), 144.5,126.3$, $123.2,121.9\left(\mathrm{~d}, J_{\mathrm{C}-\mathrm{F}}=9.8 \mathrm{~Hz}\right), 121.4,119.6,116.3\left(\mathrm{~d}, J_{\mathrm{C}-\mathrm{F}}=25.3 \mathrm{~Hz}\right), 115.0\left(\mathrm{~d}, J_{\mathrm{C}-\mathrm{F}}=1.9 \mathrm{~Hz}\right), 113.1(\mathrm{~d}$, $\left.J_{\mathrm{C}-\mathrm{F}}=1.1 \mathrm{~Hz}\right), 112.9\left(\mathrm{~d}, J_{\mathrm{C}-\mathrm{F}}=20.7 \mathrm{~Hz}\right), 111.1$; HRMS (ESI): calcd. for $\mathrm{C}_{15} \mathrm{H}_{9} \mathrm{FNO}[\mathrm{M}+\mathrm{H}]^{+} 238.0663$; found 238.0650 .

9-Chlorobenzofuro[3,2-c]quinoline (2s): Light yellow solid (0.16 g, 69\%), m.p. $155-157{ }^{\circ} \mathrm{C} .{ }^{1} \mathrm{H}-\mathrm{NMR}$ $\left(400 \mathrm{MHz}, \mathrm{CDCl}_{3}\right) \delta 9.46(\mathrm{~s}, 1 \mathrm{H}), 8.32(\mathrm{~d}, J=8.8 \mathrm{~Hz}, 1 \mathrm{H}), 8.24(\mathrm{~d}, J=1.9 \mathrm{~Hz}, 1 \mathrm{H}), 8.07(\mathrm{~d}, J=7.6 \mathrm{~Hz}, 1 \mathrm{H})$, $7.74(\mathrm{~d}, J=8.2 \mathrm{~Hz}, 1 \mathrm{H}), 7.63(\mathrm{dd}, J=8.8,2.0 \mathrm{~Hz}, 1 \mathrm{H}), 7.58-7.53(\mathrm{~m}, 1 \mathrm{H}), 7.50-7.46(\mathrm{~m}, 1 \mathrm{H}) .{ }^{13} \mathrm{C}-\mathrm{NMR}$ 
$\left(100 \mathrm{MHz}, \mathrm{CDCl}_{3}\right) \delta 156.2,154.9,146.7,144.4,134.2,128.0,126.9,126.5,123.2,121.4,121.1,119.7,115.6$, 114.5, 111.1; HRMS (ESI): calcd. for $\mathrm{C}_{15} \mathrm{H}_{9} \mathrm{ClNO}[\mathrm{M}+\mathrm{H}]^{+}$254.0367; found 254.0367.

9-Methylbenzofuro[3,2-c]quinoline (2t): Yellow-green solid (0.18 g, 92\%), m.p. $159-161{ }^{\circ} \mathrm{C} .{ }^{1} \mathrm{H}-\mathrm{NMR}$ $\left(400 \mathrm{MHz}, \mathrm{CDCl}_{3}\right) \delta 9.44(\mathrm{~s}, 1 \mathrm{H}), 8.30(\mathrm{~d}, J=8.4 \mathrm{~Hz}, 1 \mathrm{H}), 8.07(\mathrm{~d}, J=7.1 \mathrm{~Hz}, 1 \mathrm{H}), 8.04(\mathrm{br} \mathrm{s}, 1 \mathrm{H}), 7.73(\mathrm{~d}$, $J=8.1 \mathrm{~Hz}, 1 \mathrm{H}), 7.54-7.50(\mathrm{~m}, 2 \mathrm{H}), 7.48-7.44(\mathrm{~m}, 1 \mathrm{H}), 2.62(\mathrm{~s}, 3 \mathrm{H}) .{ }^{13} \mathrm{C}-\mathrm{NMR}\left(100 \mathrm{MHz}, \mathrm{CDCl}_{3}\right) \delta 156.6$, $154.8,146.7,143.3,138.7,128.1,128.0,126.0,122.9,121.8,119.5,114.7,114.0,111.0,21.0$; HRMS (ESI): calcd. for $\mathrm{C}_{16} \mathrm{H}_{12} \mathrm{NO}[\mathrm{M}+\mathrm{H}]^{+}$234.0913; found 234.0909.

Benzofuro[3,2-c]quinolin-9-ol (2u): White solid (0.03 g, 15\%), m.p. $>250{ }^{\circ} \mathrm{C} .{ }^{1} \mathrm{H}-\mathrm{NMR}(400 \mathrm{MHz}$, DMSO- $\left._{6}\right) \delta 10.39(\mathrm{~s}, 1 \mathrm{H}), 9.53(\mathrm{~s}, 1 \mathrm{H}), 8.28-8.25(\mathrm{~m}, 2 \mathrm{H}), 7.88(\mathrm{~d}, J=8.1 \mathrm{~Hz}, 1 \mathrm{H}), 7.58-7.54(\mathrm{~m}, 1 \mathrm{H}), 7.50$ $(\mathrm{dd}, J=7.5,6.8 \mathrm{~Hz}, 1 \mathrm{H}), 7.47(\mathrm{~d}, J=2.1 \mathrm{~Hz}, 1 \mathrm{H}), 7.34(\mathrm{dd}, J=8.9,2.3 \mathrm{~Hz}, 1 \mathrm{H}) .{ }^{13} \mathrm{C}-\mathrm{NMR}(100 \mathrm{MHz}$, DMSO- $d_{6}$ ) $\delta 158.8,157.0,154.9,149.0,145.1,126.9,124.2,122.4,121.9,120.8,119.6,113.7,111.9,111.3$, 109.9; HRMS (ESI): calcd. for $\mathrm{C}_{15} \mathrm{H}_{10} \mathrm{NO}_{2}[\mathrm{M}+\mathrm{H}]^{+}$236.0706; found 236.0709.

10-Methylbenzofuro[3,2-c]quinoline (2v): Off-white solid (0.17 g, 79\%), m.p. $203-204{ }^{\circ} \mathrm{C} .{ }^{1} \mathrm{H}-\mathrm{NMR}$ $\left(400 \mathrm{MHz}, \mathrm{CDCl}_{3}\right) \delta 9.49(\mathrm{~s}, 1 \mathrm{H}), 8.27(\mathrm{~d}, J=8.0 \mathrm{~Hz}, 1 \mathrm{H}), 8.10(\mathrm{~d}, J=7.6 \mathrm{~Hz}, 1 \mathrm{H}), 7.74(\mathrm{~d}, J=8.2 \mathrm{~Hz}, 1 \mathrm{H})$, $7.64(\mathrm{~d}, J=6.6 \mathrm{~Hz}, 1 \mathrm{H}), 7.60-7.52(\mathrm{~m}, 2 \mathrm{H}), 7.48-7.45(\mathrm{~m}, 1 \mathrm{H}), 2.91(\mathrm{~s}, 3 \mathrm{H}) .{ }^{13} \mathrm{C}-\mathrm{NMR}\left(100 \mathrm{MHz}, \mathrm{CDCl}_{3}\right)$

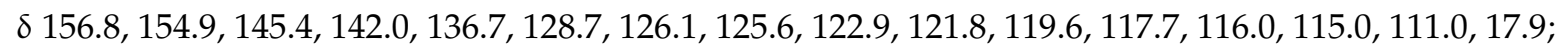
HRMS (ESI): calcd. for $\mathrm{C}_{16} \mathrm{H}_{12} \mathrm{NO}[\mathrm{M}+\mathrm{H}]^{+}$234.0913; found 234.0906 .

9-Bromobenzofuro[3,2-c]quinolin-4-ol (2w): Light pink solid (0.05 g, 17\%), m.p. $>250{ }^{\circ} \mathrm{C} .{ }^{1} \mathrm{H}-\mathrm{NMR}$ $\left(400 \mathrm{MHz}, \mathrm{DMSO}-d_{6}\right) \delta 9.71-9.63(\mathrm{~m}, 2 \mathrm{H}), 8.41(\mathrm{~s}, 1 \mathrm{H}), 8.32(\mathrm{~d}, J=8.6 \mathrm{~Hz}, 1 \mathrm{H}), 7.90(\mathrm{~d}, J=8.3 \mathrm{~Hz}, 1 \mathrm{H})$, $7.72(\mathrm{~d}, J=8.8 \mathrm{~Hz}, 1 \mathrm{H}), 7.62(\mathrm{~s}, 1 \mathrm{H}), 7.06(\mathrm{~d}, J=8.4 \mathrm{~Hz}, 1 \mathrm{H}) .{ }^{13} \mathrm{C}-\mathrm{NMR}\left(100 \mathrm{MHz}\right.$, DMSO- $\left.d_{6}\right) \delta 156.8$, 154.6, 149.3, 147.2, 146.5, 131.5, 130.3, 122.6, 122.5 (2C), 116.8, 116.2, 115.3, 112.6, 106.1; HRMS (ESI): calcd. for $\mathrm{C}_{15} \mathrm{H}_{9} \mathrm{BrNO}_{2}[\mathrm{M}+\mathrm{H}]^{+}$314.9844; found 314.0560.

9-Chlorobenzofuro[3,2-c]quinolin-4-ol (2x): Pink solid (0.03 g, 12\%), m.p. $>250{ }^{\circ} \mathrm{C} .{ }^{1} \mathrm{H}-\mathrm{NMR}(400 \mathrm{MHz}$, DMSO-d 6 ) $\delta 9.86($ br s, $1 \mathrm{H}), 9.62(\mathrm{~s}, 1 \mathrm{H}), 8.38(\mathrm{~d}, J=8.8 \mathrm{~Hz}, 1 \mathrm{H}), 8.23(\mathrm{~d}, J=1.9 \mathrm{~Hz}, 1 \mathrm{H}), 7.77(\mathrm{dd}, J=8.8$, $2.0 \mathrm{~Hz}, 1 \mathrm{H}), 7.71(\mathrm{~d}, J=8.9 \mathrm{~Hz}, 1 \mathrm{H}), 7.63(\mathrm{~d}, J=2.4 \mathrm{~Hz}, 1 \mathrm{H}), 7.09(\mathrm{dd}, J=8.9,2.4 \mathrm{~Hz}, 1 \mathrm{H}) .{ }^{13} \mathrm{C}-\mathrm{NMR}$ $\left(100 \mathrm{MHz}, \mathrm{DMSO}-d_{6}\right) \delta 156.7,154.7,149.2,147.0,146.5,133.8,128.3,127.7,122.5,116.7,116.2,115.1$, 112.5, 106.1; HRMS (ESI): calcd. for $\mathrm{C}_{15} \mathrm{H}_{9} \mathrm{ClNO}_{2}[\mathrm{M}+\mathrm{H}]^{+}$270.0316; found 270.0318.

\subsection{Cell Line and Culture Conditions}

The cell lines used in this study were obtained from the American Type Culture Collection (ATCC). The MV-4-11 cell line and peripheral blood mononuclear cells (PBMCs) were cultured in RMPI 1640 medium (Shanghai Weike Biotechnology Co. Ltd, Shanghai, China) supplemented with $10 \%$ FBS (fatal bovine serum). All cells were grown at $37^{\circ} \mathrm{C}$ in a $5 \% \mathrm{CO}_{2}$ atmosphere.

\subsection{Cell Viability Assay}

The MV-4-11 cells and peripheral blood mononuclear cells (PBMCs) were seeded in 96-well plates at 10,000 cells per well and treated with compounds at the indicated concentrations and time intervals (3 days). The number of viable cells was assessed using CellTiter $96^{\circledR}$ Aqueous Non-Radioactive Cell Proliferation Assay (Promega), according to the manufacturer's protocol. The absorbance of the formazan at $490 \mathrm{~nm}$ was detected using SpectraMax ${ }^{\circledR} 340$ PC384 (Molecular Device).

\section{Conclusions}

In summary, we have developed an efficient sequential chlorination/demethylation, intramolecular annulation reaction for the synthesis of a variety of substituted benzofuro[3,2-c]quinolines starting from 3-(2-methoxyphenyl)quinolin-4(1H)ones. This sequential transformation was metal-free and was conducted under mild reaction conditions. An in vitro biological evaluation indicated that these compounds showed excellent antileukemia activity and selectivity, and therefore may offer a promising hit compound for further antileukemia studies. 
Supplementary Materials: The following are available online. Table S1: Condition optimization for the dimethyl-cyclization (one-pot). Table S2: Condition optimization for the cyclization (stepwise). Table S3: Condition optimization for the cyclization from $4 \mathbf{a}$ to $2 \mathbf{a}$.

Author Contributions: Conceptualization, J.T.; data curation, G.-Y.X.; investigation, Y.L. and W.-B.W.; methodology, Y.-B.Z.; supervision, L.-F.Y., J.T., Y.-B.Z., J.L., and F.Y.; writing-original draft, Y.L. and D.X.; Writing-review and editing, F.Y. All authors have read and agreed to the published version of the manuscript.

Funding: Financial support from the national Natural Science Foundation of China (21772043) is greatly acknowledged.

Conflicts of Interest: The authors declare no conflict of interest.

\section{References}

1. Bennett, F.; Kezar, H.S., III; Girijavallabhan, V.; Huang, Y.H.; Huelgas, R.; Rossman, R.; Shih, N.Y.; Piwinski, J.J.; MacCoss, M.; Kwong, C.D.; et al. Pyridofuran substituted pyrimidine derivatives as HCV replication (replicase) inhibitors. Bioorg. Med. Chem. Lett. 2012, 22, 5144-5149. [CrossRef]

2. Ciustea, M.; Silverman, J.E.Y.; Druck Shudofsky, A.M.; Ricciardi, R.P. Identification of Non-Nucleoside DNA Synthesis Inhibitors of Vaccinia Virus by High-Throughput Screening. J. Med. Chem. 2008, 51, 6563-6570. [CrossRef]

3. Martini, M.L.; Ray, C.; Yu, X.F.; Liu, J.; Pogorelov, V.M.; Wetsel, W.C.; Huang, X.P.; McCorvy, J.D.; Caron, M.G.; Jin, J. Designing Functionally Selective Noncatechol Dopamine D1 Receptor Agonists with Potent In Vivo Antiparkinsonian Activity. ACS Chem. Neuro. 2019, 10, 4160-4182. [CrossRef]

4. Zheng, X.Z.; Bauer, P.; Baumeister, T.; Buckmelter, A.J.; Caligiuri, M.; Clodfelter, K.H.; Han, B.S.; Ho, Y.C.; Kley, N.; Lin, J.; et al. Structure-Based Discovery of Novel Amide-Containing Nicotinamide Phosphoribosyltransferase (Nampt) Inhibitors. J. Med. Chem. 2013, 56, 6413-6433. [CrossRef]

5. Lv, Y.C.; Li, M.Y.; Liu, T.; Tong, L.J.; Peng, T.; Wei, L.X.; Ding, J.; Xie, H.; Duan, W.H. Discovery of a New Series of Naphthamides as Potent VEGFR-2 Kinase Inhibitors. ACS Med. Chem. Lett. 2014, 5, 592-597. [CrossRef]

6. Sutherland, H.S.; Tong, A.S.T.; Choi, P.J.; Conole, D.; Blaser, A.; Franzblau, S.G.; Cooper, C.B.; Upton, A.M.; Lotlikar, M.U.; Denny, W.A.; et al. Structure-activity relationships for analogs of the tuberculosis drug bedaquiline with the naphthalene unit replaced by bicyclic heterocycles. Bioorg. Med. Chem. 2018, 26, 1797-1809. [CrossRef] [PubMed]

7. Chen, Y.; Lin, H.Z.; Yang, H.Y.; Tan, R.X.; Bian, Y.Y.; Fu, T.M.; Li, W.; Wu, L.; Pei, Y.Q.; Sun, H.P. Discovery of new acetylcholinesterase and butyrylcholinesterase inhibitors through structure-based virtual screening. RSC Adv. 2017, 7, 3429-3438. [CrossRef]

8. Wu, P.C.; Huang, Y.B.; Chang, C.K.; Chen, Y.L.; Tzeng, C.C.; Tsai, Y.H. Highly Sensitive Quantitative Analysis of 1-[3-(Furo[3,2-c]quinolin-4-ylamino)phenyl]ethanone Oxime, a New Antitumor Agent, in Rat Plasma by LC with Electrochemical Detection. Chromatographia 2009, 70, 265-269. [CrossRef]

9. Vaidya, A.; Jain, S.; Jain, A.K.; Prashanthakumar, B.R.; Kashaw, S.K.; Agrawal, R.K. Computational analysis of quinoline derivatives as potent topoisomerase-II inhibitors. Med. Chem. Res. 2015, 24, 383-393. [CrossRef]

10. Shanahan, R.M.; Hickey, A.; Reen, F.J.; O'Gara, F.; McGlacken, G.P. Synthesis of Benzofuroquinolines via Phosphine-Free Direct Arylation of 4-Phenoxyquinolines in Air. Eur. J. Org. Chem. 2018, 2018, 6140-6149. [CrossRef]

11. Luo, W.R.; Yu, Z.C.; Qiu, W.W.; Yang, F.; Liu, X.F.; Tang, J. One-pot production of chiral $\alpha, \beta$-epoxy ketones from benzaldehydes and acetophenones by recyclable poly(amino acid) catalysis. Tetrahedron 2011, 67, 5289-5292. [CrossRef]

12. Wang, S.; Zhao, C.; Liu, T.; Yu, L.F.; Yang, F.; Tang, J. Efficient construction of 3-arylquinolin-4(1 H )-ones via in situ Meinwald rearrangement/intramolecular reductive cyclization of 2'-nitrochalcone epoxides. Tetrahedron 2016, 72, 7025-7031. [CrossRef]

13. Hong, F.L.; Chen, Y.W.; Lu, B.L.; Cheng, J.J. One-Pot Assembly of Fused Heterocycles via Oxidative Palladium-Catalyzed Cyclization of Arylols and Iodoarenes. Adv. Synth. Catal. 2016, 358, 353-357. [CrossRef]

14. Ji, F.H.; Li, X.W.; Wu, W.Q.; Jiang, H.F. Palladium-Catalyzed Oxidative Carbonylation for the Synthesis of Polycyclic Aromatic Hydrocarbons (PAHs). J. Org. Chem. 2014, 79, 11246-11253. [CrossRef] [PubMed] 
15. Kawase, Y.; Yamaguchi, S.; Maeda, O.; Hayashi, A.; Hayashi, I.; Tabata, K.; Kondo, M. The Synthesis of Benzofuroquinolins. I. Some Benzofuro[2,3-b]quinoline and Benzofuro[3,2-c]quinoline Derivatives. J. Heterocyclic Chem. 1979, 16, 487-491. [CrossRef]

16. Tummatorn, J.; Krajangsri, S.; Norseeda, K.; Thongsornkleeb, C.; Ruchirawat, S. A new synthetic approach to 6-unsubstituted phenanthridine and phenanthridine-like compounds under mild and metal-free conditions. Org. Biomol. Chem. 2014, 12, 5077-5081. [CrossRef]

17. Mehra, M.K.; Tantak, M.P.; Kumar, I.; Kumar, D. Microwave-Assisted Metal- and Ligand-Free O-Arylation of Quino- lones Using Diaryliodonium Salts: An Easy and Rapid Synthesis of Aryloxyquinolines. Synlett 2016, 27, 604-610.

18. Bao, Y.S.; Agula, B.; Zhaorigetu, B.; Jia, M.L.; Baiyin, M.H. One pot synthesis of diarylfurans from aryl esters and $\mathrm{PhI}(\mathrm{OAc})_{2}$ via palladium-associated iodonium ylides. Org. Biomol. Chem. 2015, 13, 4179-4182. [CrossRef]

19. Zhang, W.; Lun, S.C.; Liu, L.L.; Xiao, S.Q.; Duan, G.F.; Gunosewoyo, H.; Yang, F.; Tang, J.; Bishai, W.R.; Yu, L.F. Identification of Novel Coumestan Derivatives as Polyketide Synthase 13 Inhibitors against Mycobacterium tuberculosis. Part II. J. Med. Chem. 2019, 62, 3575-3589. [CrossRef]

20. Yamada, T.; Saito, N.; Anraku, M.; Imai, T.; Otagiri, M. Physicochemical Characterization of a New Crystal Form and Improvements in the Pharmaceutical Properties of the Poorly Water-Soluble Antiosteoporosis Drug 3,9-bis(N,N-Dimethylcarbamoy-loxy)-5H-benzofuro[3,2-c]quinoline-6-one (KCA-098) by Solid Dispersion with Hydroxypropylcellulose. Pharm. Dev. Technol. 2000, 5, 443-454.

21. Zhang, W.; Lun, S.C.; Wang, S.H.; Jiang, X.W.; Yang, F.; Tang, J.; Manson, A.L.; Earl, A.M.; Gunosewoyo, H.; Bishai, W.R.; et al. Identification of Novel Coumestan Derivatives as Polyketide Synthase 13 Inhibitors against Mycobacterium tuberculosis. J. Med. Chem. 2018, 61, 791-803. [CrossRef] [PubMed]

22. Quentmeier, H.; Reinhardt, J.; Zaborski, M.; Drexler, H.G. FLT3 mutations in acute myeloid leukemia cell lines. Leukemia 2003, 17, 120-124. [CrossRef] [PubMed]

23. Han, S.Y.; Ahn, J.H.; Shin, C.Y.; Choi, S.U. Effects of indirubin derivatives on the FLT3 activity and growth of acute myeloid leukemia cell lines. Drug Develop. Res. 2010, 71, 221-227. [CrossRef]

24. Nemes, Z.; Takács-Novák, K.; Völgyi, G.; Valko, K.; Béni, S.; Horváth, Z.; Szokol, B.; Breza, N.; Dobos, J.; Szántai-Kis, C.; et al. Synthesis and characterization of amino acid substituted sunitinib analogues for the treatment of AML. Bioorg. Med. Chem. Lett. 2018, 28, 2391-2398. [CrossRef]

25. Chen, H.Q.; Xie, J.; Xing, D.; Wang, J.P.; Tang, J.; Yi, Z.F.; Xia, F.; Qiu, W.W.; Yang, F. Diastereoselective synthesis of 3,3-disubstituted 3-nitro-4-chromanone derivatives as potential antitumor agents. Org. Biomol. Chem. 2019, 17, 1062-1066. [CrossRef]

Sample Availability: Samples of the compounds are not available from the authors.

(C) 2020 by the authors. Licensee MDPI, Basel, Switzerland. This article is an open access article distributed under the terms and conditions of the Creative Commons Attribution (CC BY) license (http://creativecommons.org/licenses/by/4.0/). 